
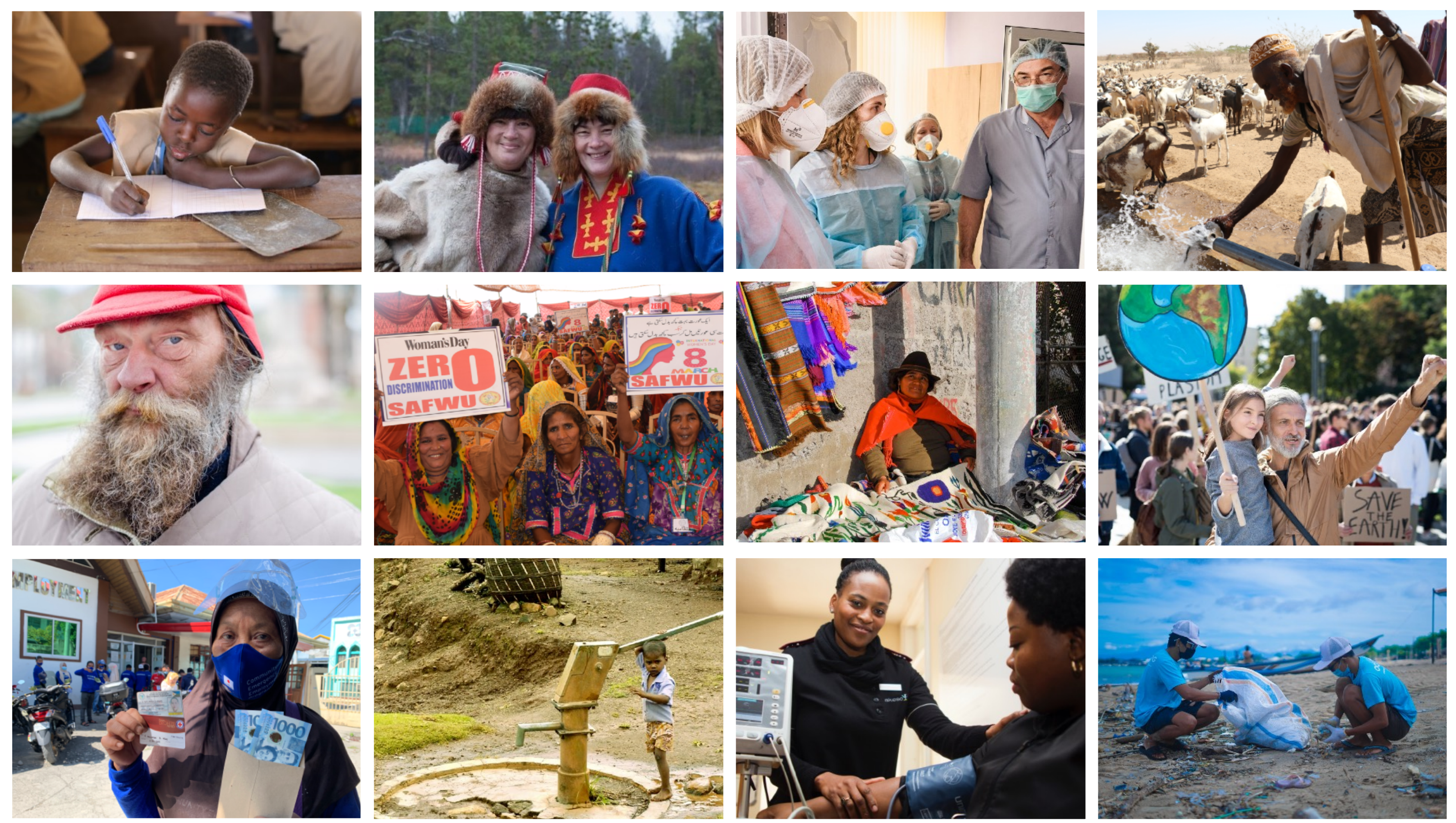

2020 Yearbook

The Committee on Economic, Social and Cultural Rights 


\section{A Message from our Executive Director}

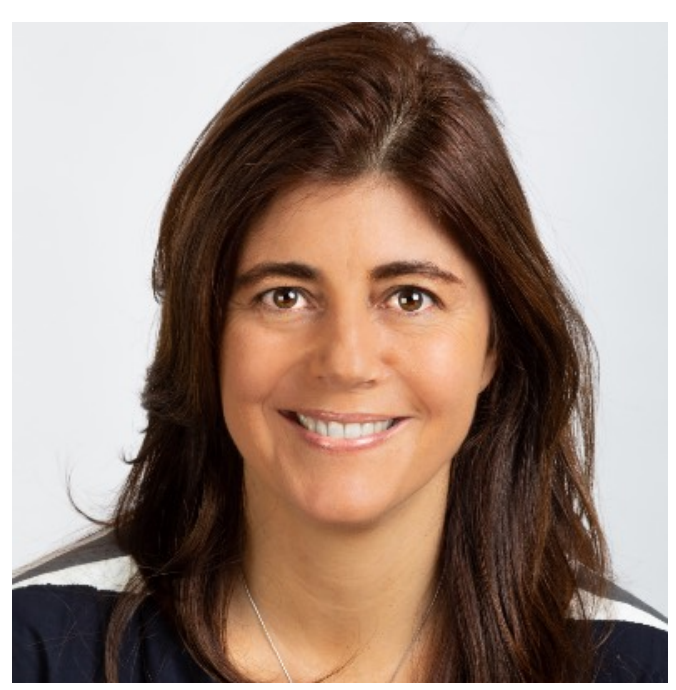

We are delighted to present the fourth edition of GI-ESCR's annual Yearbook of the Committee on Economic, Social and Cultural Rights (CESCR). The Yearbook captures the full breadth of the activities that the Committee has engaged in through the year and promises to be a helpful tool for civil society organisations, academics, States and all those interested in the potential of economic, social and cultural rights to transform structures of poverty and marginalisation.

2020 was a year like no other. Only 5 days after the close of the Committee's first session, the World Health Organization officially declared that the coronavirus outbreak had developed into a pandemic. The Committee adapted to work online during this period when its mandate assumed heightened significance and, as you will see in the pages that follow, engaged in a concerted effort to address all dimensions of the coronavirus crisis, as well as issues as wide ranging as the climate emergency, evictions, gender equality and land rights.

By publishing the CESCR Yearbook each year GI-ESCR plays an important role in making the work of the Committee more prominent and accessible. Used wisely, the guidance that this important body provides may be critical in shaping the world we wish to build as we emerge from the coronavirus pandemic. The stakes have never been higher.

\section{Magdalena Sepúlveda Carmona}

Executive Director of GI-ESCR 


\section{A Message from the Committee Chair}

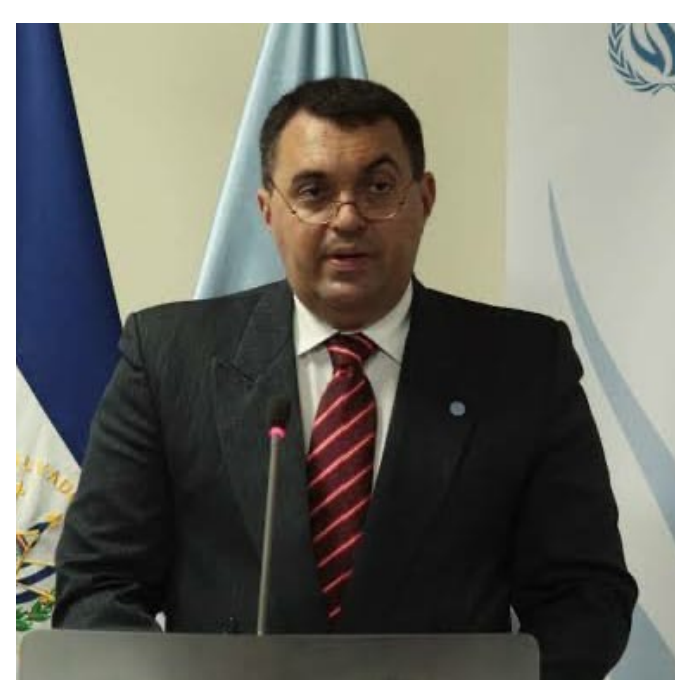

I am proud to introduce the latest edition of the annual Yearbook of the Committee on Economic, Social and Cultural Rights (CESCR). The Yearbook offers a comprehensive articulation of the wide range of activities that the Committee has been engaged with over this most extraordinary of years.

I speak of course of the coronavirus pandemic, which continues have an enormous impact on the economic, social and cultural rights of individuals across the world. As you will see in the Yearbook, the Committee has gone to great lengths to address the multiples crises that the pandemic has ignited, publishing two separate Statements on the impact of the crisis and access to vaccines in 2020, as well as a further Statement on vaccination, international cooperation and intellectual property in 2021.

Alongside our work on State reports, individual communications and general comments, the Committee is also very pleased to have agreed to move towards a predictable review cycle and offer all States the simplified reporting procedure. Whilst this decision is a significant step forward, effective implementation will ultimately depend on the resources that are made available to the Committee.

My colleagues on the Committee deserve great praise for their commitment to ensuring that Committee sessions could be moved online during the period when in-person meetings have not been possible, with members working at many different hours of the day and connecting from a range of time zones. I would also like to use this opportunity express my appreciation of colleagues who completed their terms in 2020, Shiqui Chen, Zdzislaw Kedzia and Sandra Liebenberg, for their valuable contributions to the work of the Committee. The Committee is now looking forward to being able to resume meeting in-person in Geneva from September 2021.

The CESCR Yearbook serves the valuable function of ensuring that the work that the Committee engages in each year is clearly understandable and accessible to human rights advocates, researchers and broader civil society. We are thankful to GI-ESCR for its ongoing engagement and support of the work of the Committee, and welcome the continued publication of the Yearbook!

\section{Renato Zerbini Ribeiro Leão}

Chair of the Committee on Economic, Social and Cultural Rights 


\section{Table of Contents}

\section{An Introduction to the CESCR}

The Committee and the

Covenant

5

State Reporting

Individual Communications

Thematic Work

The Committee in 2020

The Composition of the

Committee

Member Nationality and

Occupation

\section{Committee}

Elections

Overview of the

Committee's work in 2020

The Committee during the COVID-19 pandemic

\section{State Reporting in 2020}

2020 overview

Key themes in 2020

Concluding Observations

Follow up to Concluding

Observations

Civil society engagement
Individual communications in 2020

20
2020 overview

2020 in context

Merits decisions

Inadmissibility

decisions

Discontinuance

decisions

Follow-up to Individual Communications

\section{Thematic Work in 2020}

General comment on Science and ESC rights

Statement on Coronavirus \& ESC Rights (April 2020)

Statement on access to vaccines for coronavirus (November 2020)

Working methods and procedural Information

Predictable review cycle \& simplified reporting procedure

Front Cover: "A young girl writes in her

notebook" by the Global Partnership fo

Education CC BY-NC-ND 2.0; "1050" by

UNICEF Ukraine CC BY 2.0; "2283" by

UNDP Ukraine CC BYNDD 2.0; "Ethiopia:

UNDP Ukran CC BYND 2.0, "Ethiopia:

worst El Niño induced drought in 50 years"

by EU Civil Protection CC BY-NC-ND 2.0

"7:30 a.m. on a cold winter day in

Barcelona" by Luis Alvarez Marra CC BY-NC

ND 2.0; Sindh Agriculture women workers

allying for their rights by ILO Asia Pacific

CC BYYNC ND 2.0:Community Emecife

CC BY-NC-ND 2.0, Communty Emergency

CC BYyC-ND 2.0 Suela by Eic Chan CC
BY 2.0; Page 18 Moisson sur les bords du Mono by Loic Pinseel CC BY-NC-ND 2.0. Page 27: "Manifestación antidesahucios" by Barcex, CC BY-SA 2.0. Page 28:Quito Old Town by Anthony Surace, CC BY-NC ND 2.0

Many thanks to Mia Abel and Amy Sarr, former interns with GIESCR, for their valuable assistance with the preparation of the 2020 CESCR Yearbook.
Coordination with the Human Rights Committee

Draft rules of procedure under the OP-ICESCR 


\section{An introduction to the CESCR}

\section{THE COMMITTEE AND THE COVENANT}

The Committee on Economic, Social and Cultural Rights (CESCR) is the expert human rights body tasked with monitoring implementation of the International Covenant on Economic, Social and Cultural Rights (ICESCR). This Covenant is a binding human rights treaty which contains human rights such as the right to just and favourable conditions of work, the right to an adequate standard of living, the right to education, and the right to take part in cultural life. It entered into force in 1976 and, following ratification by Oman in 2020, now has 171 State parties.

The Committee has three key functions which enable it to monitor State compliance with their obligations under the Covenant:

\section{1) Reviewing States through the Reporting Procedure}

The Committee reviews periodic State reports in which parties to the Covenant must detail the measures that they have taken to realise the rights of those within their jurisdiction.

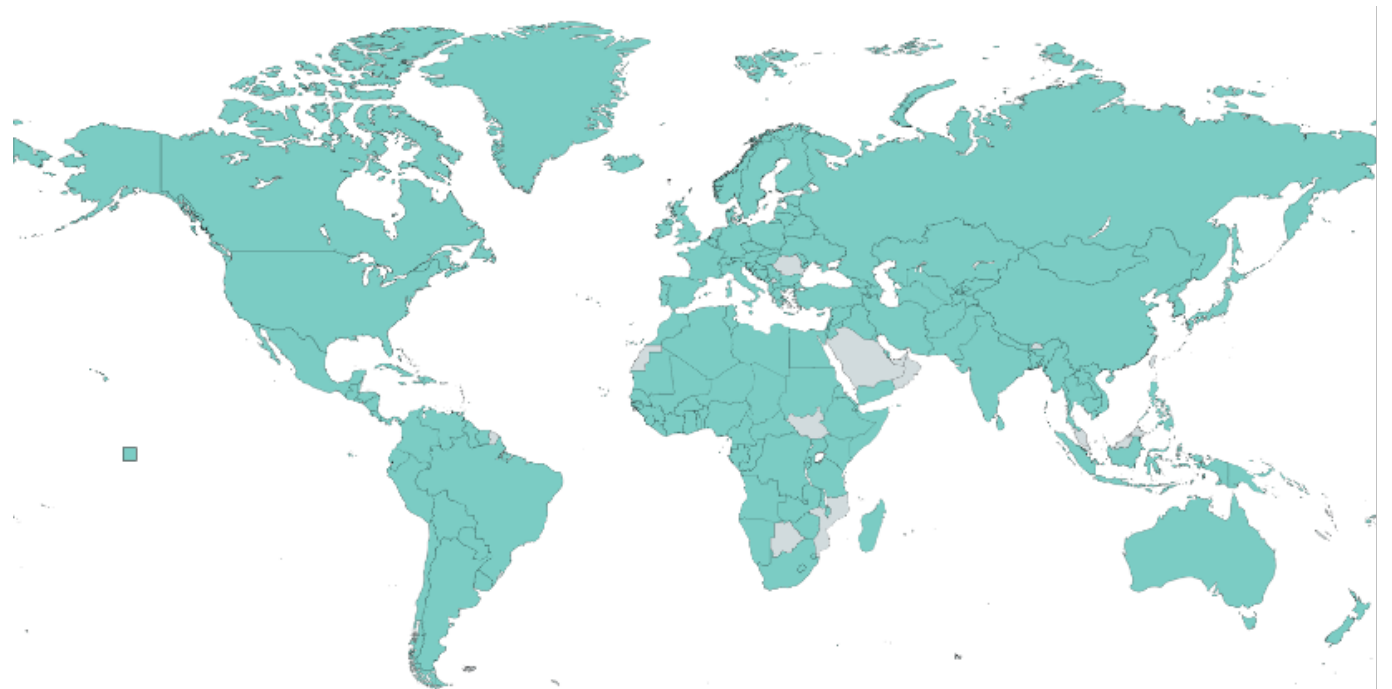

There are now 171 State parties to the International Covenant on ESC Rights

\section{2) Developing General Comments, Statements and other thematic work}

The Committee develops the jurisprudential framework of economic, social and cultural (ESC) rights through the drafting of General Comments. It also publishes Statements and Open Letters in which it clarifies Covenant obligations and applies them to pressing thematic issues.

\section{3) Considering Individual Communications under the Optional Protocol}

Since the entry into force of an Optional Protocol (OP) to the ICESCR in 2013, the Committee has been empowered to consider complaints brought by individuals who allege that their Covenant rights have been violated by a State party to the OP. Following ratification by Armenia and the Maldives in 2020 , there are now a total of 26 State parties to the OP, as well as 46 signatories.

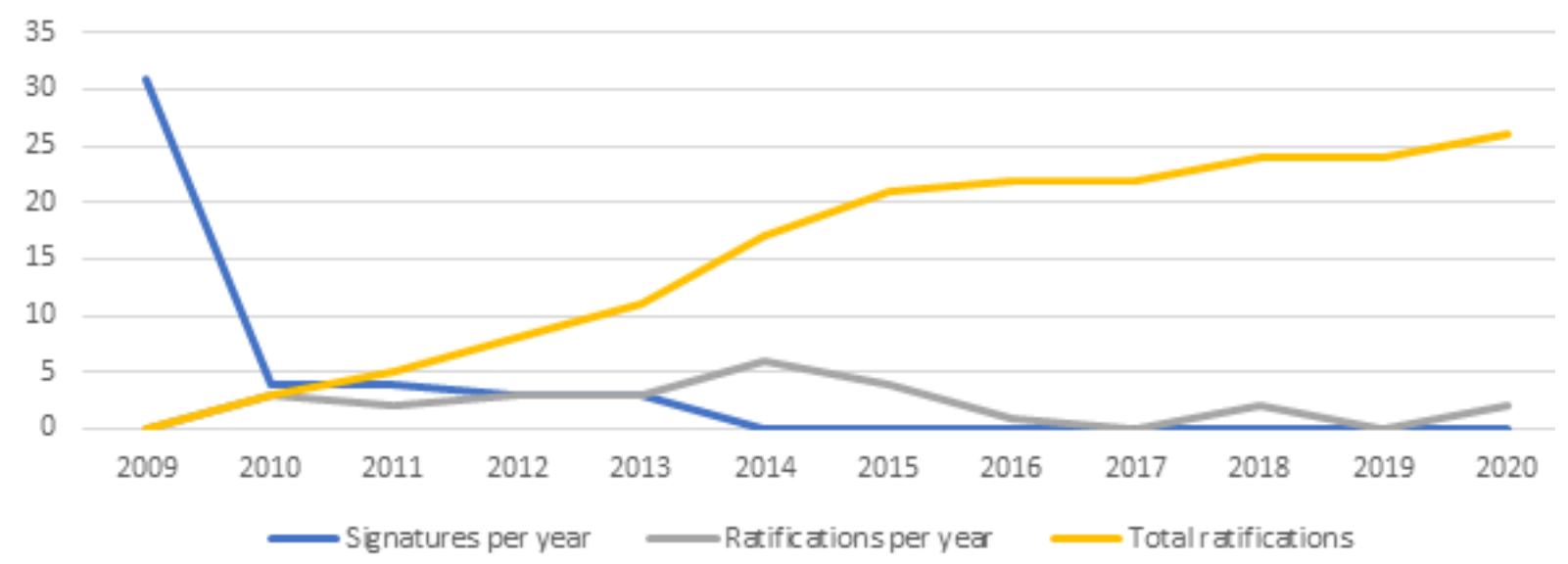

Signatures and ratifications of the Optional Protocol to the ICESCR (including accessions). 


\section{The State Reporting}

\section{Procedure}

The Committee's State reporting procedure enables it to periodically assess the progress that States have made towards realising Covenant rights.

\section{STAGE 1: The state report}

The first stage of the State reporting procedure differs depending on whether the State under review wishes to follow the standard reporting procedure, or the simplified reporting procedure.
If a State opts to follow the standard reporting procedure, it must first submit a periodic report to the CESCR in which it details the measures that it has adopted to realise ESC rights.
A pre-sessional working group of the Committee then considers this report and prepares a List of Issues ( $\mathrm{LOI}$ ) in which it requests any additional information it considers necessary for the review. The State then replies to the LOI in a shorter report.
If a State avails itself of the simplified reporting procedure, the reporting process begins with a pre-sessional working group of the Committee preparing a List of Issues Prior to Reporting (LOIPR)
The LOIPR requests information on the issues that the Committee considers necessary to conduct a review of the State's implementation of the Covenant.

The State then submits a response the Committee's questions, with this response constituting its periodic report to the CESCR. 


\section{STAGE 2: In-session dialogue}

The Committee then invites a delegation of the reviewed State to Geneva, where it hosts a six-hour constructive dialogue on the State's periodic report. The dialogue allows Committee members to comment on the progress of the reviewed State and pose direct questions to representatives from various ministries.

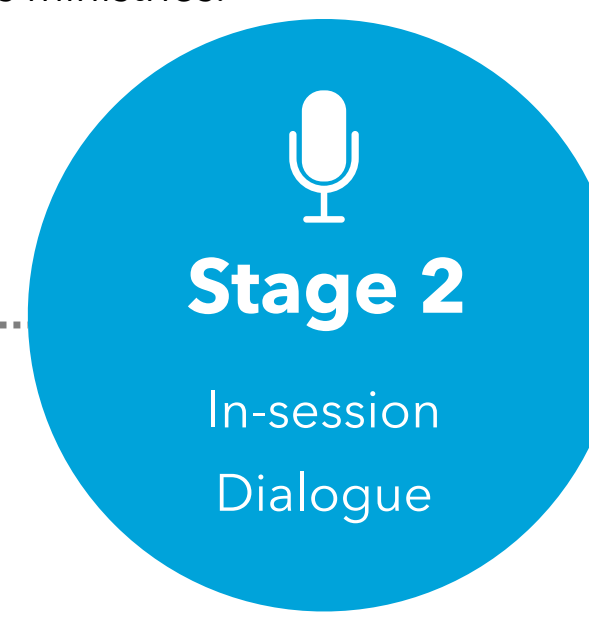

STAGE 3: COBS

Following the dialogue, the Committee adopts a set of Concluding Observations (COBs) on the State review. The observations consist primarily of concerns that the Committee has identified during the course of the review, as well as recommendations for how the reviewed State can improve ESC rights realisation.

\section{STAGE 4: Follow-up to COBs}

In each set of $\mathrm{COBs}$, the Committee selects up to three recommendations for its follow-up procedure. These are recommendations that "require urgent attention" and "should be attainable within a period of 24 months".
Within these 24 months States are required to produce a report on the action that they have taken to implement them. The Committee then assesses the compliance of the State and, for each recommendation, gives it a grade of either "sufficient progress"; "insufficient progress"; "lack of sufficient information to make an assessment"; or "no response".

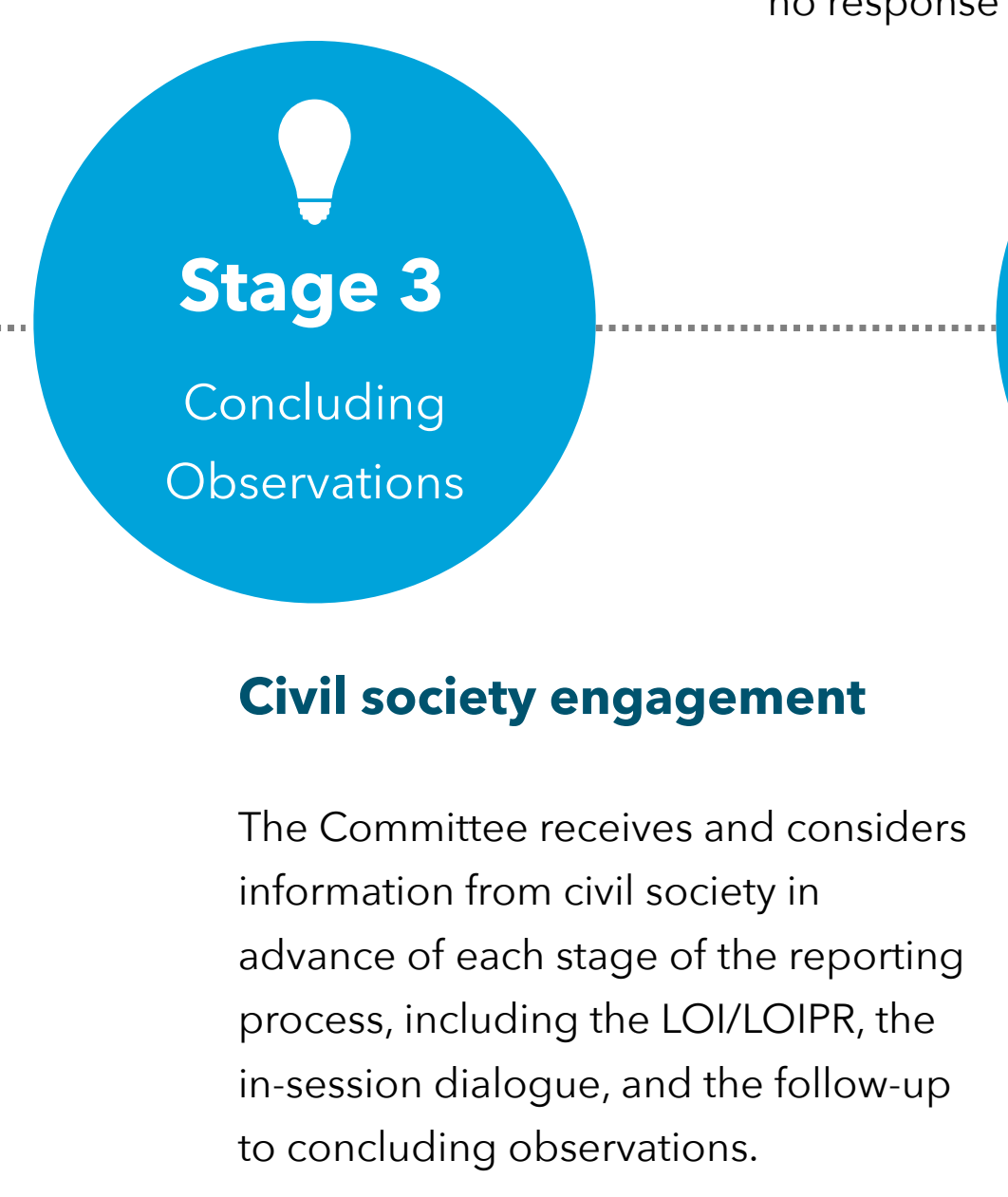

These civil society reports - referred to as "shadow" or "parallel" reports - play a crucial role informing the Committee

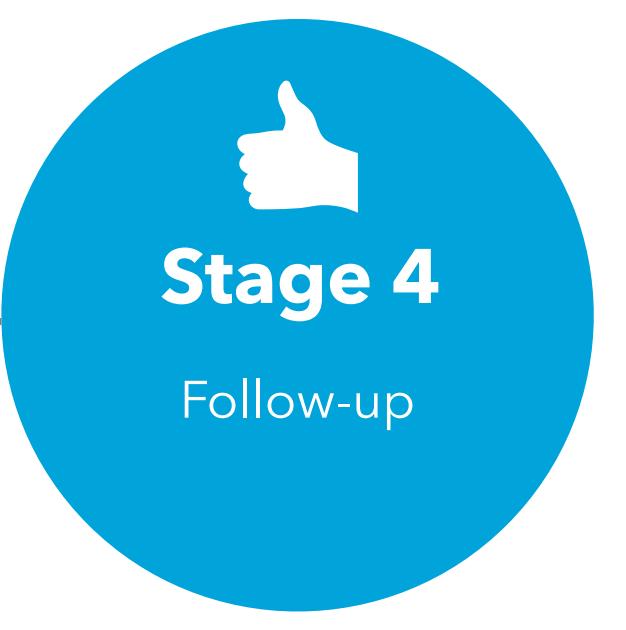

of important human rights issues and identifying economic, social and cultural developments that have been neglected in the State's own report.

Alongside civil society organisations, national human rights institutions and UN agencies can also submit reports to the Committee. Civil society organisations may also deliver formal and informal oral briefings to Committee members. 


\section{Individual Communications}

Under the Optional Protocol to the International Covenant on Economic, Social and Cultural Rights the Committee may consider individual complaints that a State Party to the Optional Protocol has violated a Covenant right.

\section{STAGE 2: Admissibility}

The Committee begins its consideration of a complaint by assessing its admissibility against criteria contained in the Optional Protocol. If it does not meet all of the criteria it will be declared inadmissible and the communication process will end.

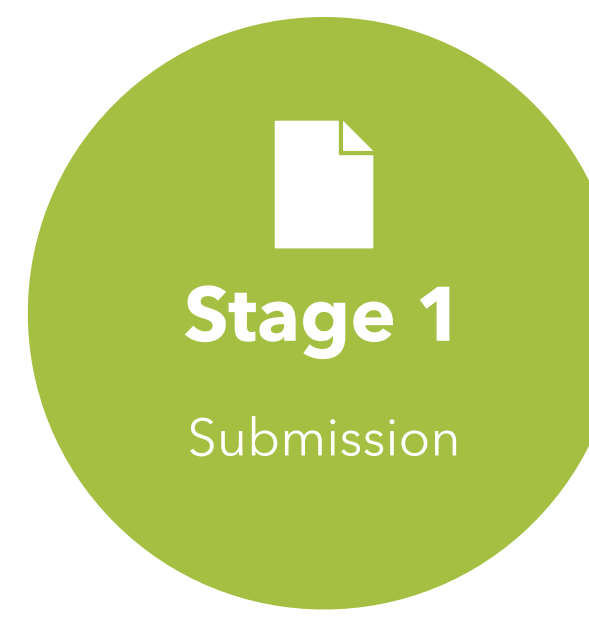

STAGE 1: Submission

The individual communication process begins with the submission of a complaint to the Committee. Upon the initial registration of the communication, the Committee may request that the respondent State take interim measures so as to avoid "possible irreparable damage" occurring before it makes a decision.

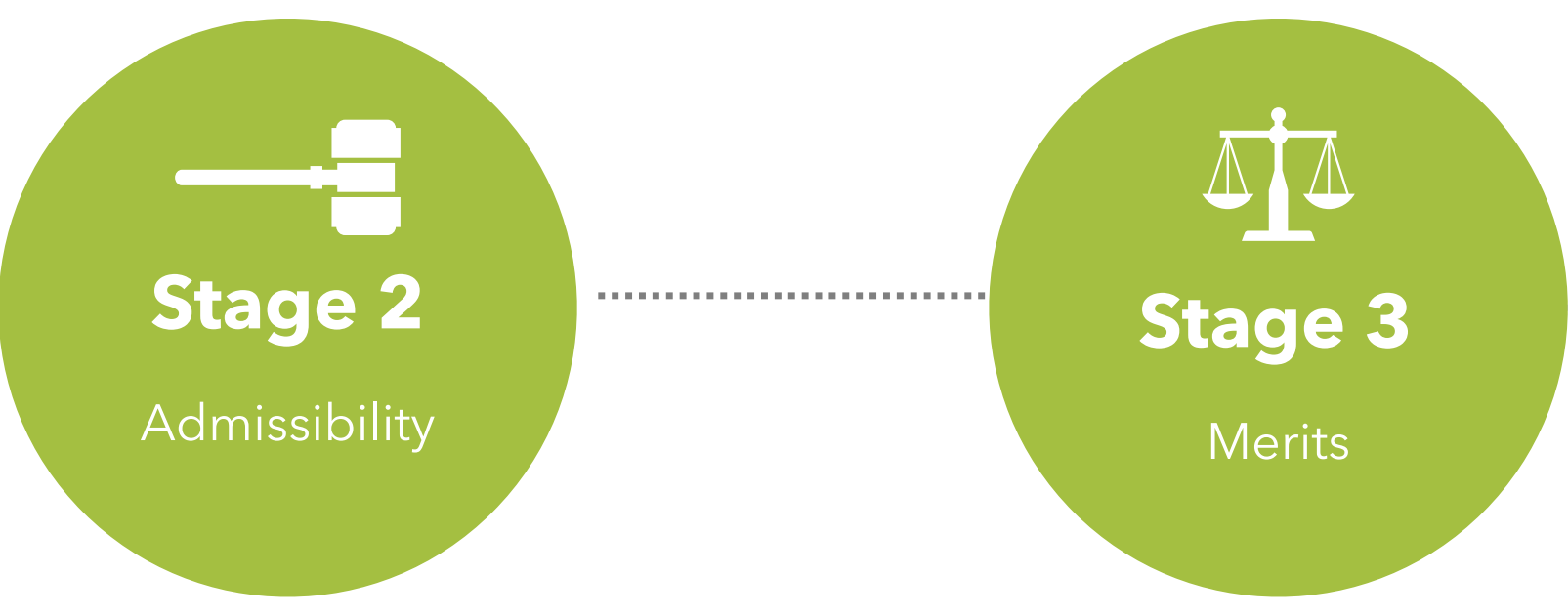

\section{STAGE 3: Merits}

If a communication is admissible, the Committee will proceed to consider it on its merits. At this stage, the Committee must determine whether the actions or omissions of the respondent State can be reasonably justified given their procedural and substantive obligations under the Covenant. The intensity of the Committee's scrutiny will vary depending on the circumstances of each case.
When the Committee engages in close scrutiny, its approach resembles proportionality analysis. Accordingly, when a State has imposed a prima facie restriction on a Covenant right, it may be asked to justify that its actions: are authorised by law; have a legitimate objective; are rationally connected to this objective; are the minimum interference with the right that will achieve the objective; and impose a burden that is not disproportionate to its benefit. 


\section{STAGE 4: Recommendations}

If the Committee establishes that the respondent State party has violated the Covenant it will make individual recommendations in respect of the author, which are specific to the case at hand (e.g., recommending payment of compensation)

\section{Discontinuance Decisions}

\section{It will also make General}

Recommendations which are designed to ensure that the respondent State party removes structural impediments to the realisation of the right in question (for example, it may recommend the implementation of new legislation).
The Committee may decide to discontinue a communication by ending it before a final determination has been reached. This may occur at the request of the author or State, or simply because the Committee has lost contact with the individual that submitted a communication.

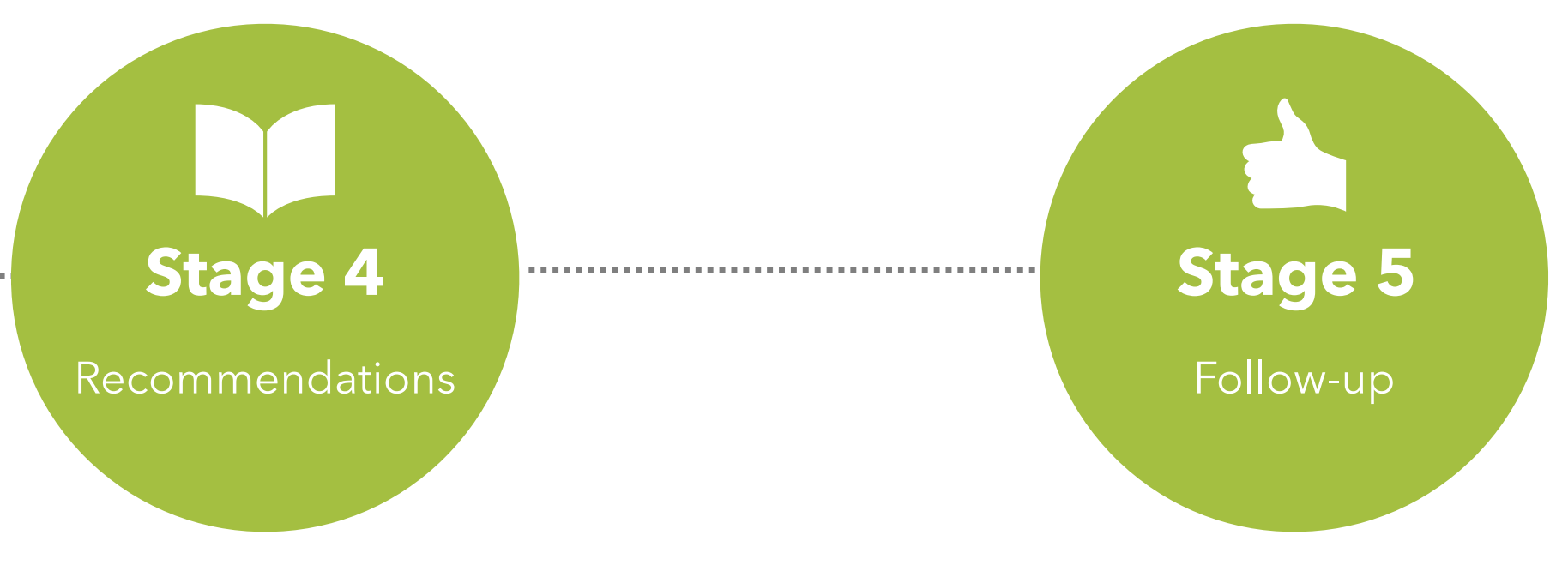

STAGE 5: Follow-up

The Optional Protocol provides the basis for a dialogical follow-up mechanism, according to which State parties are given six months to submit a report on the measures that they have taken to implement the Committee's recommendations.
The Committee then assesses whether the State has satisfactorily implemented its Views. If it determines that they have not done so, it will keep the communication under review and request further action or information. 


\section{General Comments, Statements and Open Letters}

The CESCR regularly provides analysis and guidance on a range of thematic issues related to ESC rights.

General Comments are used to provide policy advice, as well as authoritative interpretations of the normative content of ESC rights and State obligations under the Covenant. They are usually formulated following a Day of Discussion with civil society and other stakeholders, who are invited to provide input at various stages in the process.

The Committee has now published a total of 25 General Comments, the most recent of which is its 2020 General Comment on science and economic, social and cultural rights. These General Comments have been cited in the jurisprudence of domestic constitutional courts across the globe, as well as by a range of other judicial bodies. The Committee is currently working on the development of a General Comment on Land and a General Comment on Sustainable Development.

The Committee has also established a practice of adopting Statements in which it sets out Covenant obligations and applies them to issues that it considers to be of importance. Shorter and more informal than General Comments, Statements afford the Committee a degree of flexibility and allow it to engage with pressing ESC rights developments.

In the past, the Committee has also made use of Open Letters as a means of establishing how Covenant obligations relate to policy developments in States that are party to the Covenant. In 2012, for example, the Chair of the Committee wrote an open letter addressing the widespread adoption of austerity measures in the wake of the financial crisis.

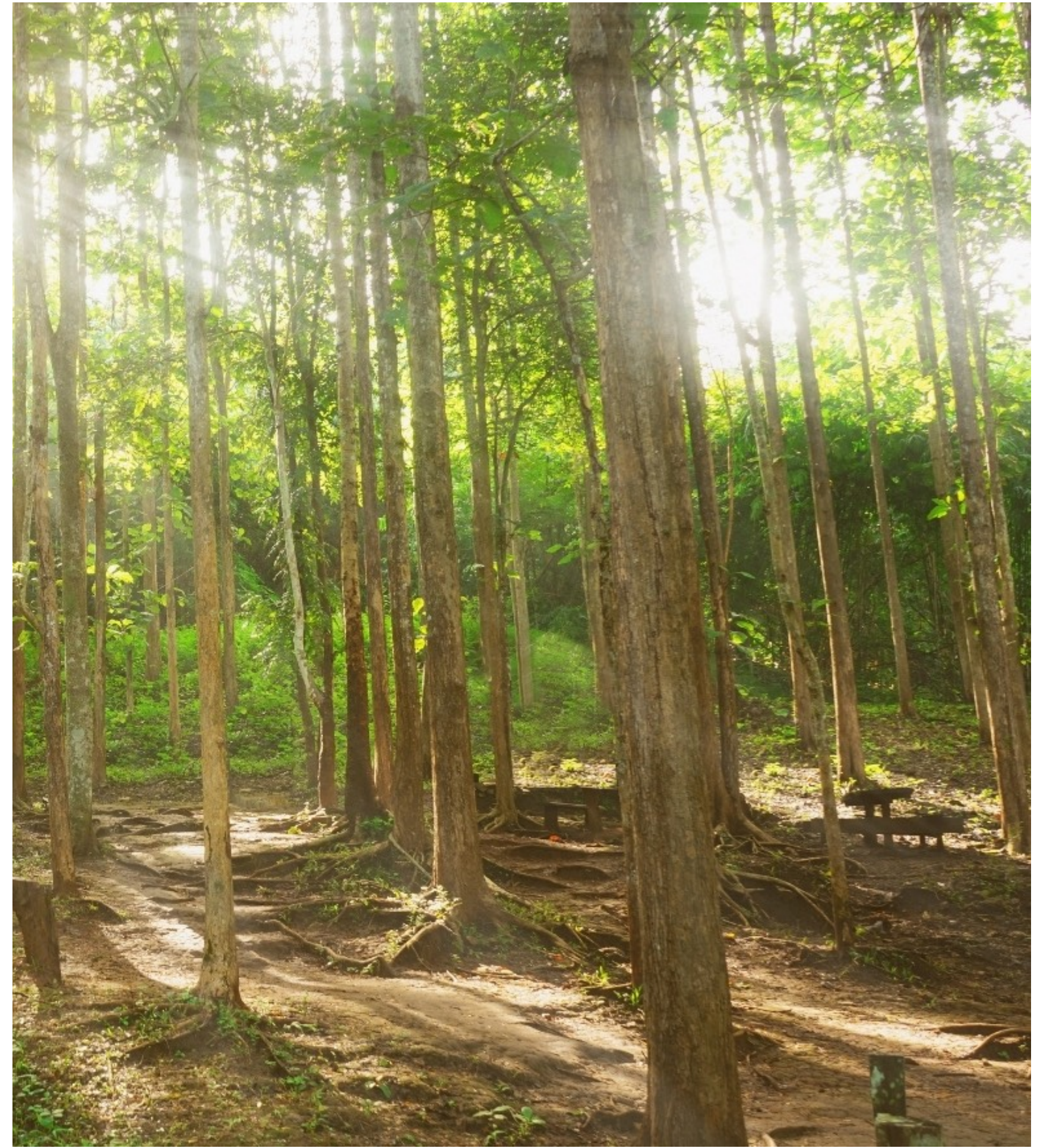

The Committee is currently working on the development of a General Comment on Land and a General Comment on Sustainable Development. 


\section{The Committee in 2020}

\section{COMPOSITION OF THE COMMITTEE}

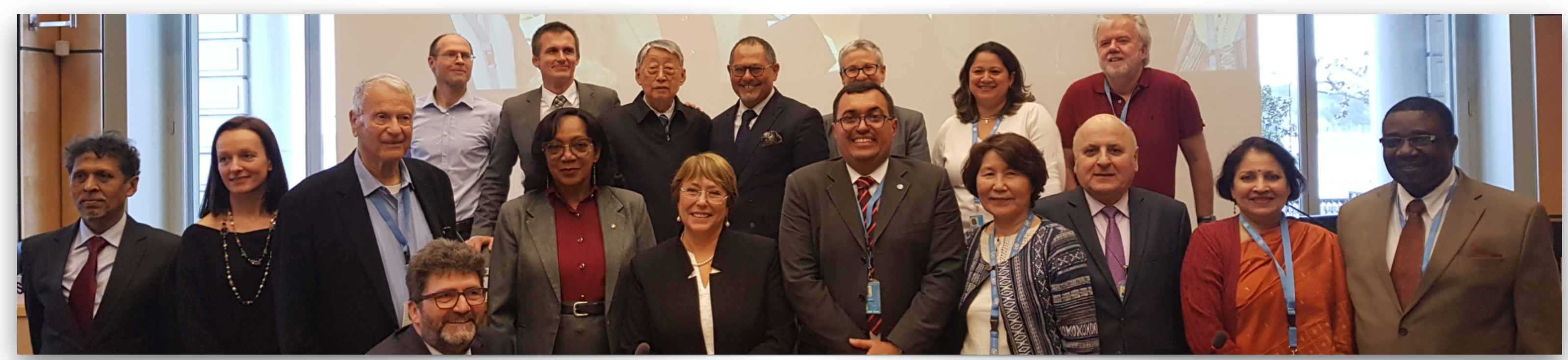

Members of the Committee, pictured in 2019 alongside Ibrahim Salama (Chief of the Human Rights Treaties Branch) and Michelle Bachelet (UN High Commissioner for Human Rights). II Mr. Renato Zerbini Ribeiro Leão
(Brazil) (Chair)
II Mr. Zdzislaw Kedzia (Poland)
If Mr. Aslan Abashidze (Russia)
I Mr. Mohamed Ezzeldin Abdel-
Moneim (Egypt)
il Mr. Asraf Ally Caunhye (Mauritius)
II Mr. Shiqiu Chen (China)
If Mr. Ludovic Hennebel (Belgium) Olivier De Schutter (Belgium)
II Mr. Michael Windfuhr (Germany)
Iํㅣㄴ. Mikel Mancisidor (Spain)
II Mr. Rodrigo Uprimny (Colombia)
II Mr. Peters Omologbe Emuze (Nigeria)

Ms. Laura-Maria
Crāciunean-Tatu (Romania)

Ms. Karla Vanessa Lemus
De Vásquez (EI Salvador)

$\begin{array}{ll}\text { (India) } & \text { Ms. Preeti Saran }\end{array}$

11 Men
Ms. Heisoo Shin
(Republic of Korea)

Ms. Lydia Ravenberg
(Suriname)

I) Ms. Sandra Liebenberg

U (South Africa) with 17 members instead of the usual 18. It returned to 18 members from 2021. 
The ECOSOC Resolution that established the Committee mandated that its membership must reflect an "equitable geographical distribution".
As such, each regional grouping is allocated a quota of seats on the Committee that accords with the number of States parties to the Covenant.
At present, "African States", "Asian States", and "Latin American and the Caribbean States" each have four seats, whilst "Eastern European States" and "Western Europe and Other States" each have 3 seats.
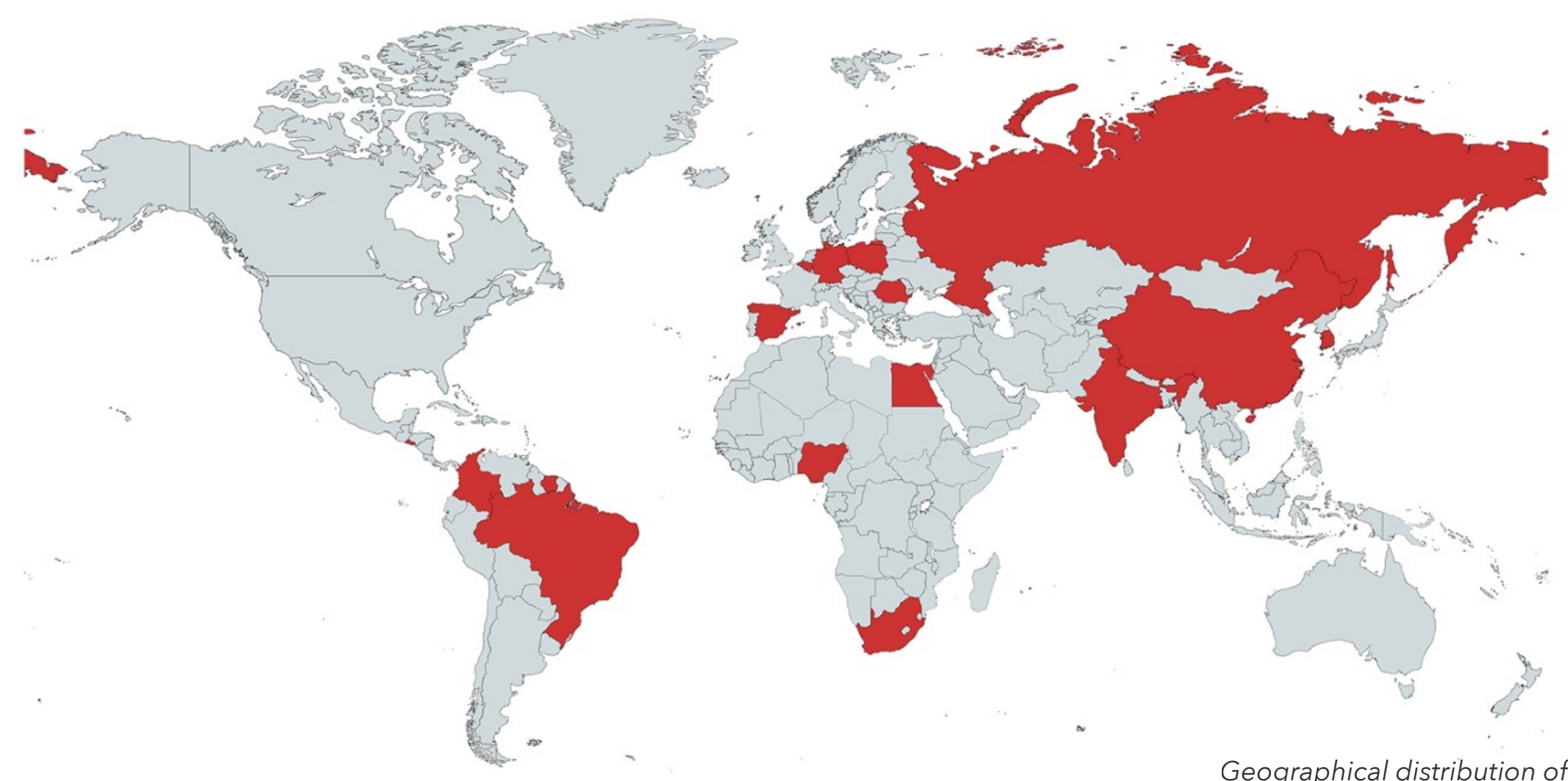

Geographical distribution of 2020 committee members.

In 2020 the Committee was composed of...

\section{Imarin ming}$$
9
$$

Academics

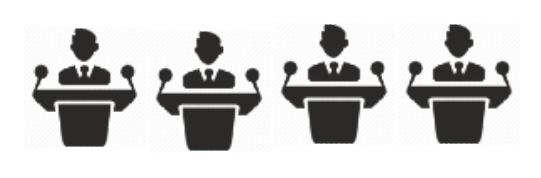

4

Current or Retired Diplomats \& Government Officials

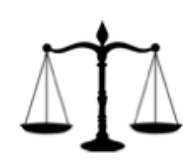

Public

Prosecutor

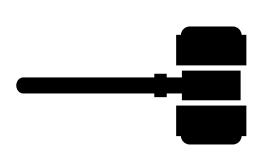

1

Judge
National Human Rights Institution Representative

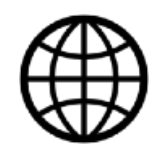

1

NGO

Director 
CESCR members are elected for a term of four years by States during elections held by ECOSOC every two years.

In 2020, elections were held for the seats of nine members whose terms were due to expire at the end of the year. Disappointingly, there were competitive elections in only two regional groups.

Mr. Abdel-Moneim (Egypt) and Mr. Amarti (Morocco) were elected to the two African seats available on the Committee, with Ms. Liebenberg
(South Africa) and Ms. Diallo (Burkina Faso) both losing out.

In the regional grouping of Western Europe and Other States Mr. Windfuhr (Germany) and Mr. Mancisidor(Spain) were both re-elected, with Ms. Elver (Turkey) failing to secure a seat.

Candidates in the regional groups of Latin America and the Caribbean, Eastern Europe, and Asia all ran unopposed. This resulted in the election of Ms. Ravenberg (Suriname), Ms. Crăciunean-Tatu (Romania) and Mr. Adilov
(Azerbaijan), and Mr. Nonthasoot (Thailand), and Mr. Yongxian Shen (China). Each new member took their seat on the Committee in January 2021.

Whilst the occupations represented on the Committee have remained broadly unchanged, the latest round of elections has further worsened the Committee's abysmal gender balance. It is now the case that only five of the Committee's 18 members are women, a serious detriment to the legitimacy of a body ostensibly mandated to further the cause of gender equality.

\section{Changes in the Committee's composition}

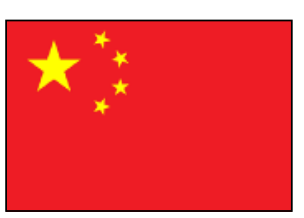

Mr. Shiqiu Chen

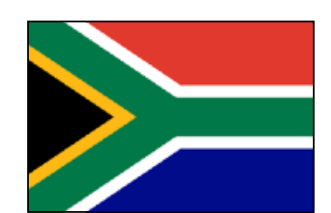

Ms. Sandra Liebenberg

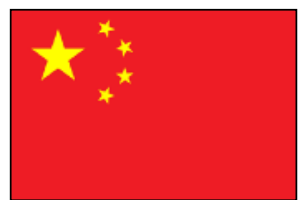

Mr. Yongxian Shen

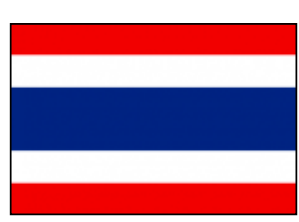

Mr. Seree

Nonthasoot

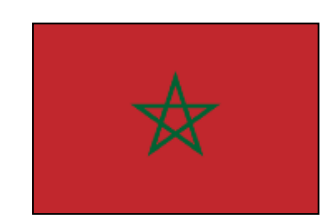

Mr. Mohammed Amarti

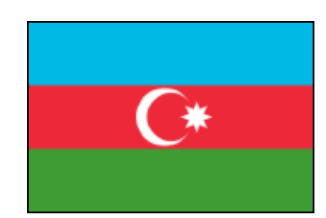

Mr. Nadir Adilov 

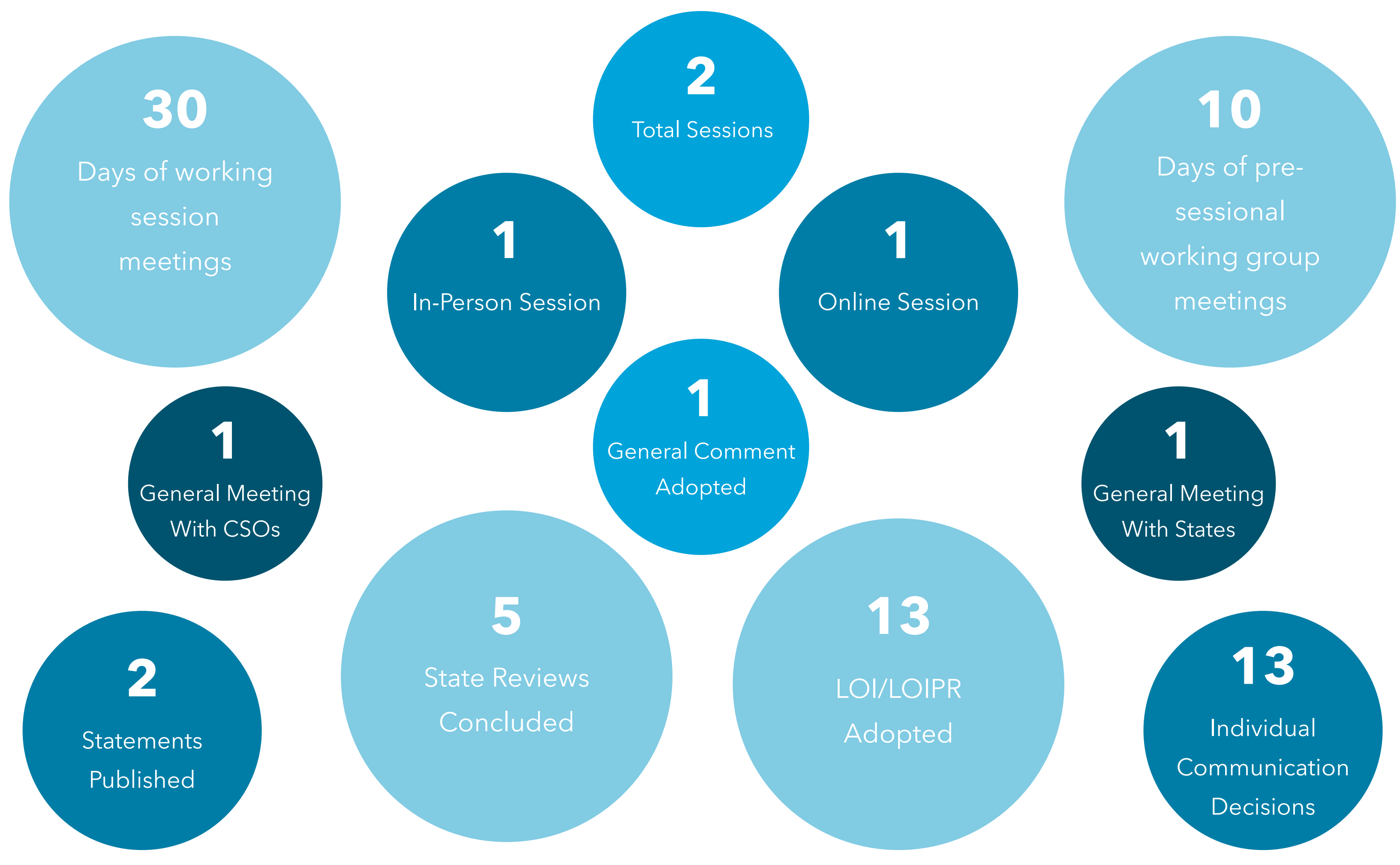


\section{The impact of COVID-19 on the Committee's work}

The Committee's first session of the year ended just five days before the World Health

Organization declared that coronavirus was officially a pandemic. It was possible to conduct the entire session in person and there was no disruption to the Committee's work at this point in time.

As the pandemic continued to spread, the Committee held its second session online, with this becoming its first ever virtual session. All six State reviews that had been scheduled for this session were postponed and the
Committee conducted most of its work in private. Both the Secretariat and Committee members made a significant effort to adapt to these conditions, with meetings taking place on multiple different platforms and across a range of different time zones.

\section{Addressing COVID-19 in the Committee's work}

The Committee made a notable effort to engage with the ongoing impact that COVID-19 has had on the full range of economic, social and cultural rights protected under the Covenant. It published two Statements in relation to the pandemic, the first of which detailed the effects of coronavirus on economic, social and cultural rights, and the second of which addressed the need

for universal and equitable access to vaccines. At a more abstract level, pandemics

were also discussed in the General Comment on science and economic, social and cultural rights.

The Committee has also used the State reporting procedure as a means of inquiring into government responses to the pandemic. For example, in a List of Issues adopted in October 2020, the Committee requested that Guatemala provide information on the "impact that the state of public emergency declared in response to the coronavirus disease (COVID-19) pandemic has had on the enjoyment of economic, social and cultural rights".

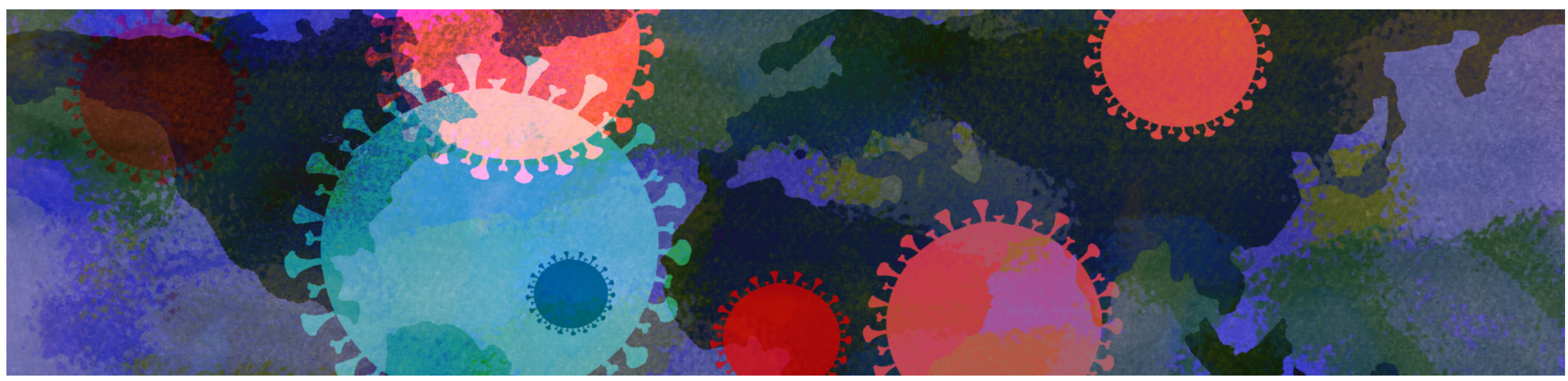

The COVID-19 pandemic has had a significant impact on the ability of all UN Treaty Bodies to fulfil their mandates. 


\section{State Reporting in 2020}

\section{OVERVIEW}

\section{States reviewed in $\mathbf{2 0 2 0}$}

Due to the disruption of the coronavirus pandemic, the Committee only reviewed 5 States in 2020: Belgium, Benin, Guinea, Norway and Ukraine. Both Norway and Ukraine opted to follow the Simplified Reporting Procedure.

\section{Follow up in 2020}

The Committee published assessments of the extent to which Mexico, Spain and New Zealand had implemented the key recommendations that it had marked for follow-up. Each of these States had been reviewed by the Committee in 2018.

The Committee also decided to send reminders to Bangladesh and the Central African Republic, whose follow-up reports had been due in 2019.

60

50

40

30

20

10

0 2011
2012
2013
2016
2017
2018
2019

\section{Overdue reports and backlog}

As at 16 October 2020, the Committee had a total of 19 State reports that were awaiting consideration: Azerbaijan, Bolivia, Bosnia and Herzegovina, Finland, Kuwait, Nicaragua, China (including Hong Kong, China, and Macao, China); Belarus; Luxembourg; Tajikistan; Panama; Lithuania; Portugal; Brazil; Cambodia; Armenia; Mauritania; Chad and Qatar.

As can be seen from the graph on the left, the onset of the coronavirus pandemic has aggravated the Committee's backlog of pending reports. Whilst the Committee's backlog has yet to reach the levels it had at the start of the last decade, continued postponement of State reviews risks erasing much of the progress that the Committee has made during this time.

The Committee considered one initial report in 2020, that of Guinea. With Oman ratifying the Covenant in 2020 the total number of States yet to submit a report remains at 27 , almost $16 \%$ of the parties to the Covenant. Of these reports, 18 are more than 10 years overdue.

Total number of pending State reports. 
The Committee engaged with a number of key themes in its 2020 Concluding Observations (COBs).

In all COBs except those on Ukraine the Committee began by analysing the domestic application of the Covenant and stressing the need for State parties to fully incorporate its rights and obligations. It raised concerns that the Covenant is rarely invoked before courts and called for State parties to inform lawyers, judges and the general population about its provisions and justiciability. The Committee also reviewed States' National Human Rights Institutions, evaluating their respective mandates and their capacity to function effectively.

The Committee considered budgetary policy in several reviews and suggested a number of different avenues through which States could maximise their available resources so as to realise ESC rights. It was particularly concerned by tax evasion and tax concessions in Ukraine, Benin and Belgium, and called on these States to implement corrective measures.

The issue of business and human rights arose in COBs addressed to Belgium and Norway. Whilst the Committee welcomed the adoption of National Action Plans in both States, it drew attention to their shortcomings and pushed for legislation that would ensure businesses could be held liable for violations of ESC rights.

In relation to extraterritorial obligations, the Committee called for a review of the investments that the Norwegian Government Pension Fund had made in businesses operating in the Occupied Palestinian Territory, including those engaged in home demolitions and the construction of Israeli settlements. It also reiterated a previous recommendation that Belgium improve international cooperation by increasing its international development assistance to $0.7 \%$ of gross domestic income.

The looming threat of climate change surfaced in relation to the reviews of Belgium and Norway. The Committee called for both to intensify their efforts to reduce greenhouse gas emissions, noting with concern that Belgium was not on track to meet its target of a $15 \%$ reduction in emissions by 2020. It advised Norway to "reconsider its decision to increase oil and natural gas exploitation" and ensure that human rights obligations are "a primary consideration in its natural resource exploitation and export policies". The extractive industries were also identified as a danger to the environment and health of local communities in the review of Guinea.

The Committee expressed concerns about discrimination in each one of the reviewed States, including against persons with albinism, disabilities and HIV/AIDS, as well as Roma, older persons, refugees, asylum seekers, internally displaced persons and those with an immigration background. It also raised concerns in relation to discrimination on the basis of gender identity and sexual orientation and called Guinea to repeal its criminalisation of same-sex relations.

Significant attention was also given to the issue of gender inequalities in all COBs, with the Committee expressing concern about the persistent discrimination that women face in their enjoyment of ESC rights. It recommended that Belgium, Norway and Ukraine intensify their efforts to reduce - and eventually eliminate - the gender wage gap; that Guinea take measures to tackle discrimination in relation to property, employment, education and polygamy; and that Benin do more to improve awareness of laws on equal rights to inheritance and land.

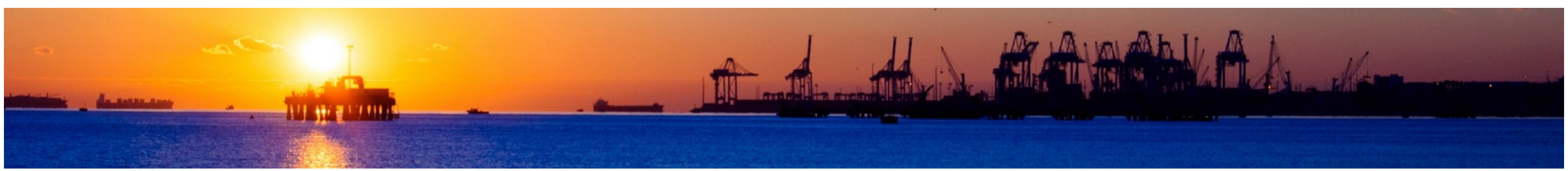

The Committee recommended that Norway reconsider its decision to increase exploitation of oil and gas reserves. 


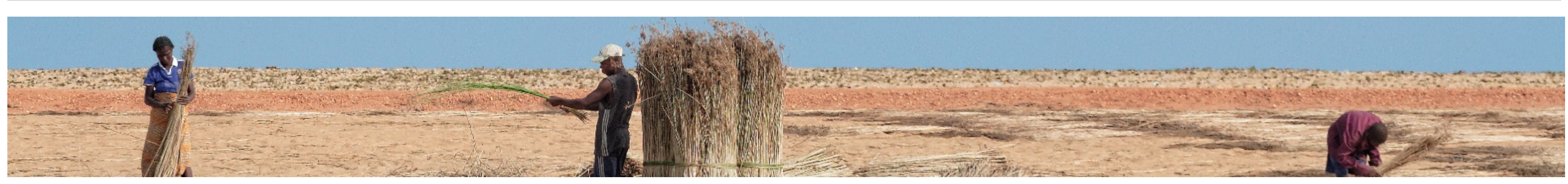

The Committee detailed its concerns at the fact that many living in Benin and Guinea continue to face food insecurity.

The Committee also expressed its dissatisfaction with the lack of affordable housing available in most of the States that it reviewed. It called on States to provide more social housing and take action to regulate the private rental market. It also advised Ukraine to establish a mechanism that would provide compensation and alternative housing to those whose property had been damaged by armed conflict.

The Committee called upon several States to strengthen access to healthcare for marginalised individuals, such as asylum seekers and refugees. Access to mental health services was also marked out as an area in which States could improve, most notably in relation to conflict-affected populations in Ukraine. The Committee also encouraged Guinea to increase provision of sexual and reproductive health services, and recommended that Benin, Norway and Ukraine take steps to decriminalise drug use.

Concerns about high levels of school drop-out in Benin, Belgium and Guinea lead the Committee to recommend urgent action to improve access to education, particularly in relation to girls and minority groups. The Committee also expressed concern regarding the persistently high illiteracy rate amongst Roma children in Norway and Ukraine, and called upon Guinea to ensure that "private education does not lead to a two-tier education system".

The Committee observed that a large number of children are being exploited by the informal economic sector in Guinea and recommended strengthening the enforcement of legislation prohibiting child labour. It also encouraged several States to intensify their efforts to combat child poverty.

Labour and trade union rights also featured across a number of COBs. The Committee drew attention to the importance of protecting domestic workers in Belgium from abuse, registered its unease with restrictions on the right to strike in Benin and Ukraine, and expressed concerns about the impact that unemployment had on groups such as women, young people and ethnic minorities in Guinea, Ukraine and Benin.

The Committee underscored the fact that a large number of people in Benin and Guinea continue to face food insecurity and recommended action be taken to assist the worst affected groups, including by diversifying income sources so as to strengthen resilience to environmental shocks. Both Benin and Belgium were also called upon to ensure that water and sanitation services remained affordable and accessible.

A number of the Committee's observations on cultural rights related to the preservation of language. It recommended that Norway secure the right of Sami children to be educated in Sami languages, that Benin introduce the teaching of national languages into school curricula, and that Ukraine ensure ethnic minorities, indigenous peoples and other groups have equal opportunities to learn their languages and use them in public and private.

Finally, the Committee also issued "Other recommendations" in each of its COBs. Amongst these, it called for the implementation of the 2030 Agenda for Sustainable Development and encouraged State parties which have not yet ratified the Optional Protocol to do so. 


\section{Follow Up}

States that were assessed in 2020 made "sufficient progress" in respect to only one of the nine key recommendations that the Committee had identified for follow-up. Whilst follow-up is drawing greater attention to the extent of State non-compliance with the Committee's recommendations, the promise of this relatively novel procedure - it was introduced in 2017 appears to be going unrealised.

\section{Spain}

Spain was also determined to have made "insufficient progress" in relation to two of the Committee's recommendations, the first of which concerned evictions, and the second of which related to the right to health and the extent to which irregular migrants may access healthcare. The Committee determined that it had "insufficient information" to make an assessment in relation to its recommendation on Spanish austerity measures.
Assessment of follow up to concluding observations.

\section{New Zealand}

New Zealand emerged with the best results of this disappointing round of follow-up assessments. The Committee noted its appreciation of the fact that the State party had adopted a range of measures in relation to its recommendation to adopt a strategy to eradicate family violence and concluded that "sufficient progress" had been made on this matter. However, it was determined that "insufficient progress" had been made in relation to recommendations that concerned New Zealand's social security sanctions regime and its national housing strategy.

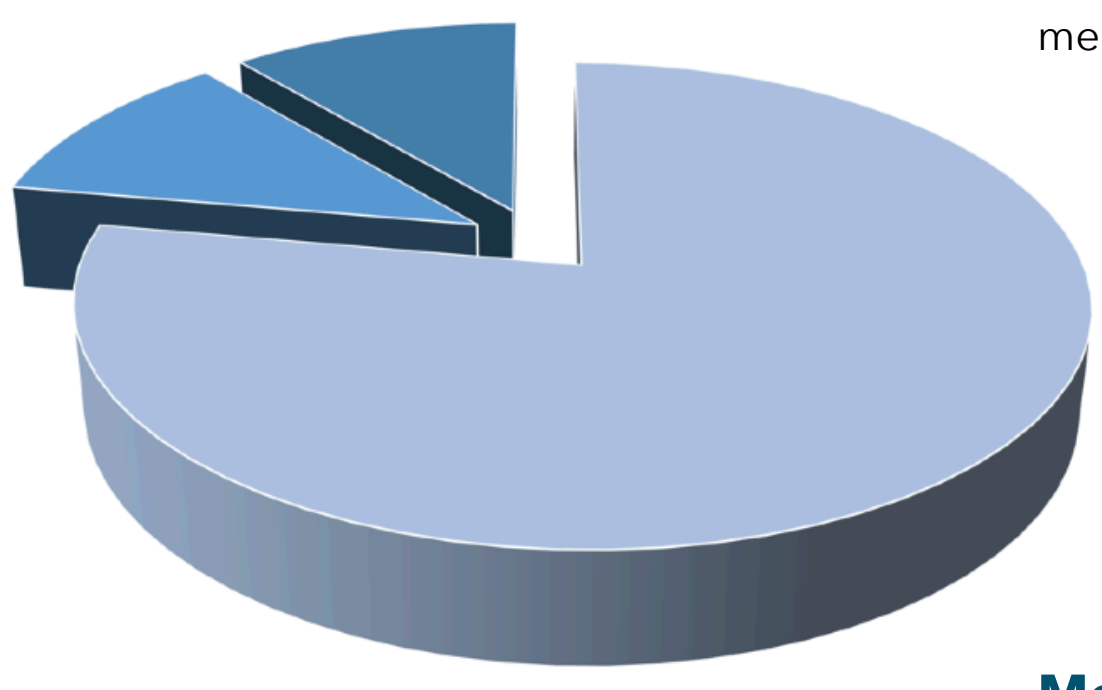

\section{Mexico}

" insufficient progress (7)

- insufficient information (1)

- sufficient progress (1)
Mexico was the only State to receive an assessment of "insufficient progress" in relation to all three of the Committee's key recommendations. This includes its recommendation on taking action to ameliorate the situation of economic, social and cultural rights defenders, its recommendation on ensuring indigenous peoples are consulted in respect of decisions that concern them, and its recommendation that Mexico implement support programmes for the relatives of disappeared persons. 


\section{States reviewed in 2020}

The Committee received a total of 45 NGO reports for the 5 States that were reviewed in 2020 .

16 of these reports were for the LOI/LOIPR, with the remaining 29 for the session. As can be seen from the graph on the right, Ukraine received the most reports (18) and Guinea the least (2).

In addition to civil society reports, across the session and the LOI/ LOIPR Norway received 3 National Human Rights Institution Reports; and Ukraine and Belgium each received 2.

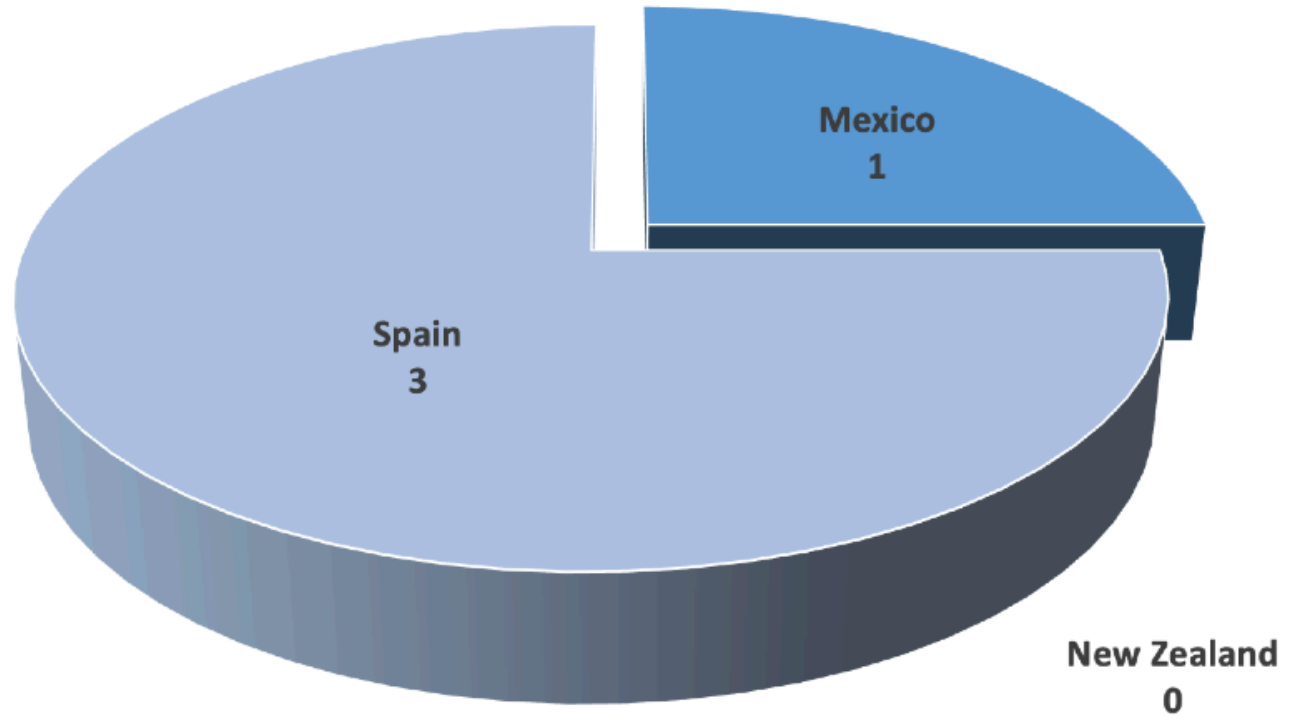

Civil society reports submitted for follow-up review

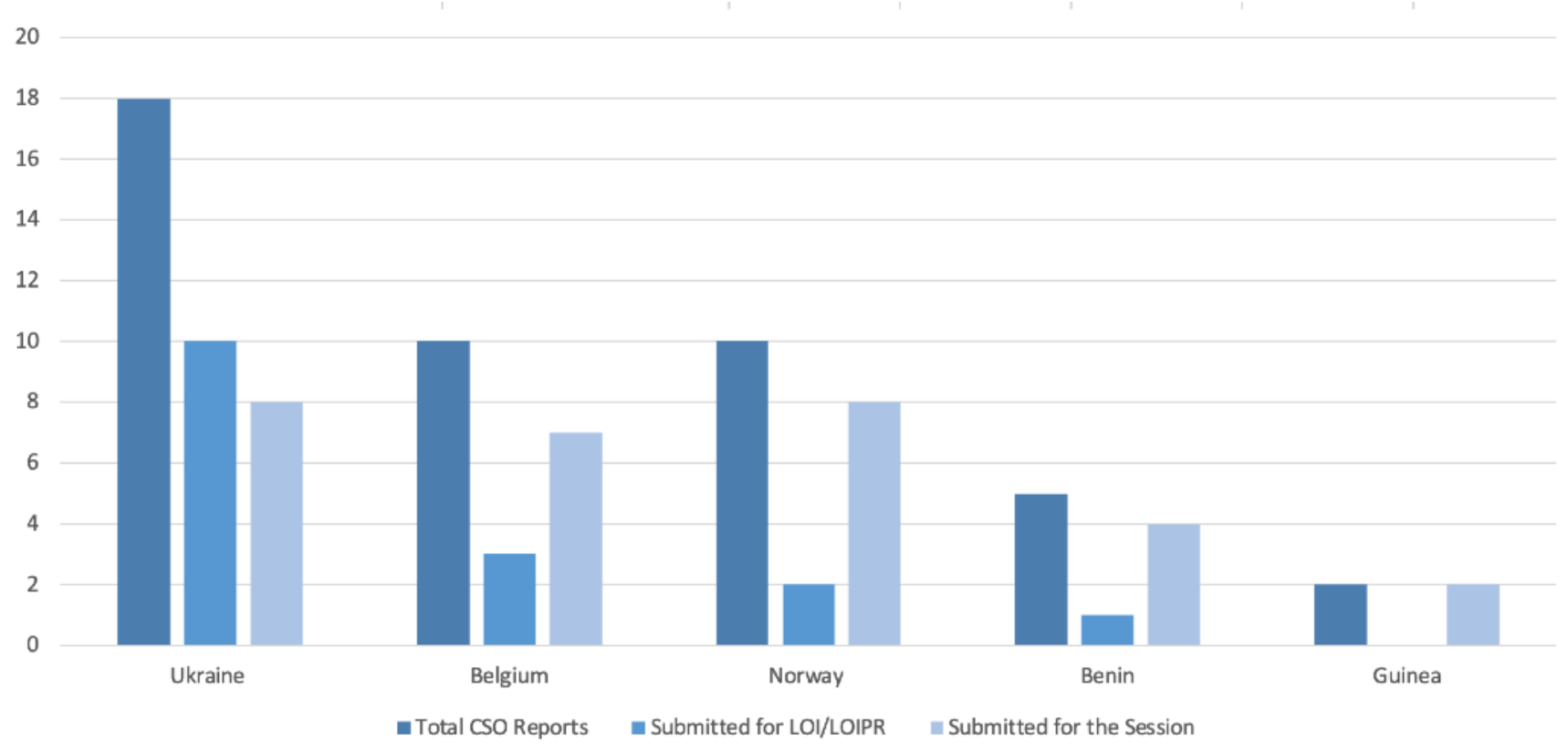

Reports submitted to the Committee by civil society organisations.

\section{Follow-Up in 2020}

Civil society engagement with the follow-up procedure was arguably better than it was in 2019, when a total of just 6 reports were submitted for 8 States. Nevertheless, the level of engagement remained poor. Only 3 civil society reports were submitted for the follow-up to the review of Spain, just 1 for Mexico, and not a single civil society report was received for the New Zealand.

The Committee is concerned about such consistently low levels of submission. Information provided by civil society provides an invaluable counterweight to the State party's own report and the work of the Committee is made much more difficult if it cannot access alternative analysis of a given State's progress. Civil society has been urged to engage more robustly with this process, whilst the secretariat has also been called upon to ensure that organisations are made aware of the deadlines by which information must be submitted. A dedicated follow-up page is now available on the Committee's website. 


\section{Individual communications in 2020}

\section{OVERVIEW}

\section{Merits decision}

- Rosario Gómez Pardo v. Spain

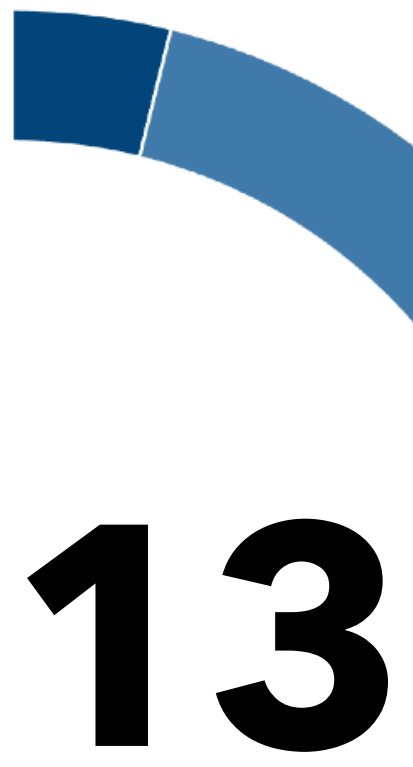

Total Decisions

- G.V.S.O.v Spain

- Luciano Daniel Juárez v Argentina

- A.M.O. and J.M.U. v Spain

- M.B.B.v Spain decisions

- M.J.J.F. and J.A.A. v Spain

- El Bahri and others v Spain

D.E.B. and L.M. v Spain

\section{H.B. et al. v Spain}

C.P.V.H.v Spain

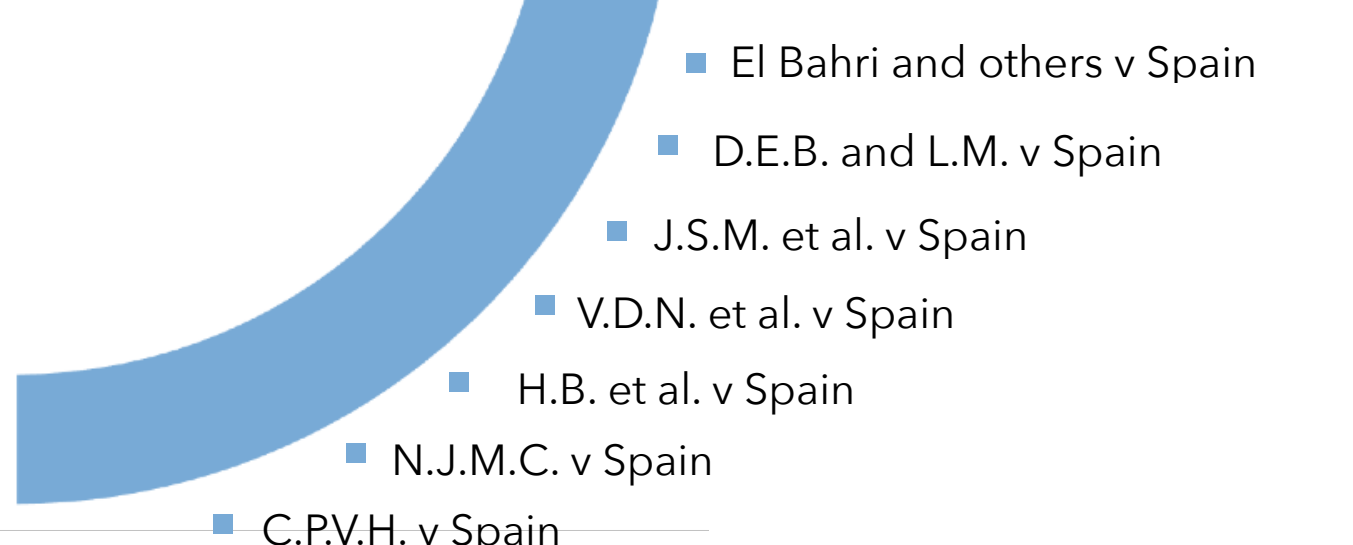

Inadmissibility decisions

\section{Discontinuance}


Communications registered and decided: 2020 saw the Committee decide seven fewer communications than it had in 2019.

Nevertheless, the gap between the number of communications registered and the number decided shrunk dramatically, a consequence of the sharp drop in the number of new communications submitted to the Committee. The comparatively low number of communications is perhaps the result of eviction moratoria being introduced by States in the context of the coronavirus pandemic. If this is indeed the case, one would expect the number of communications to soar once such moratoria are lifted.

Backlog: The persistence of a gap between communications decided and registered entails that the Committee's backlog continued to grow in 2020, albeit at a slower rate. At the close of the year, there were a total of 151 communications pending. If the Committee continues to make the same number of annual decisions as it did in 2020, the backlog will take almost 12 years to clear.

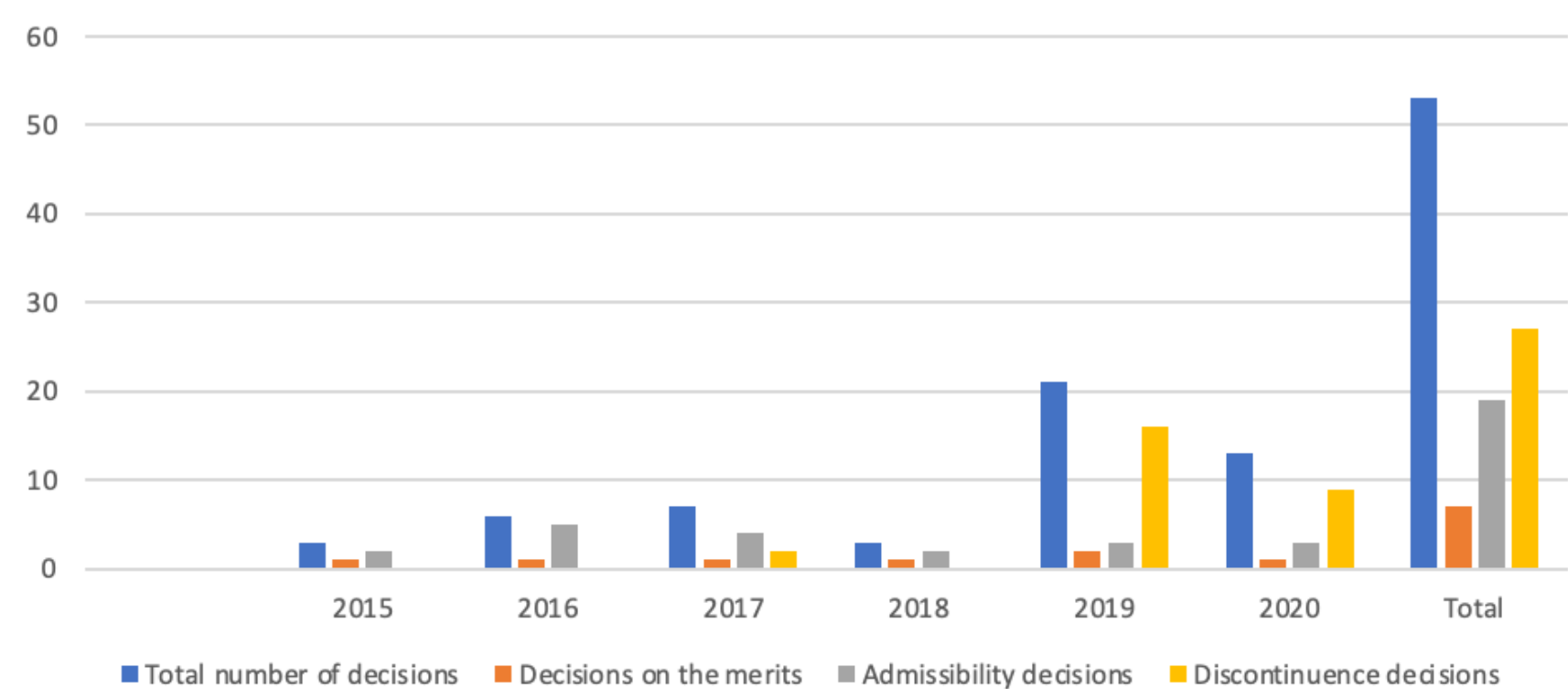

Committee decisions each year by type.

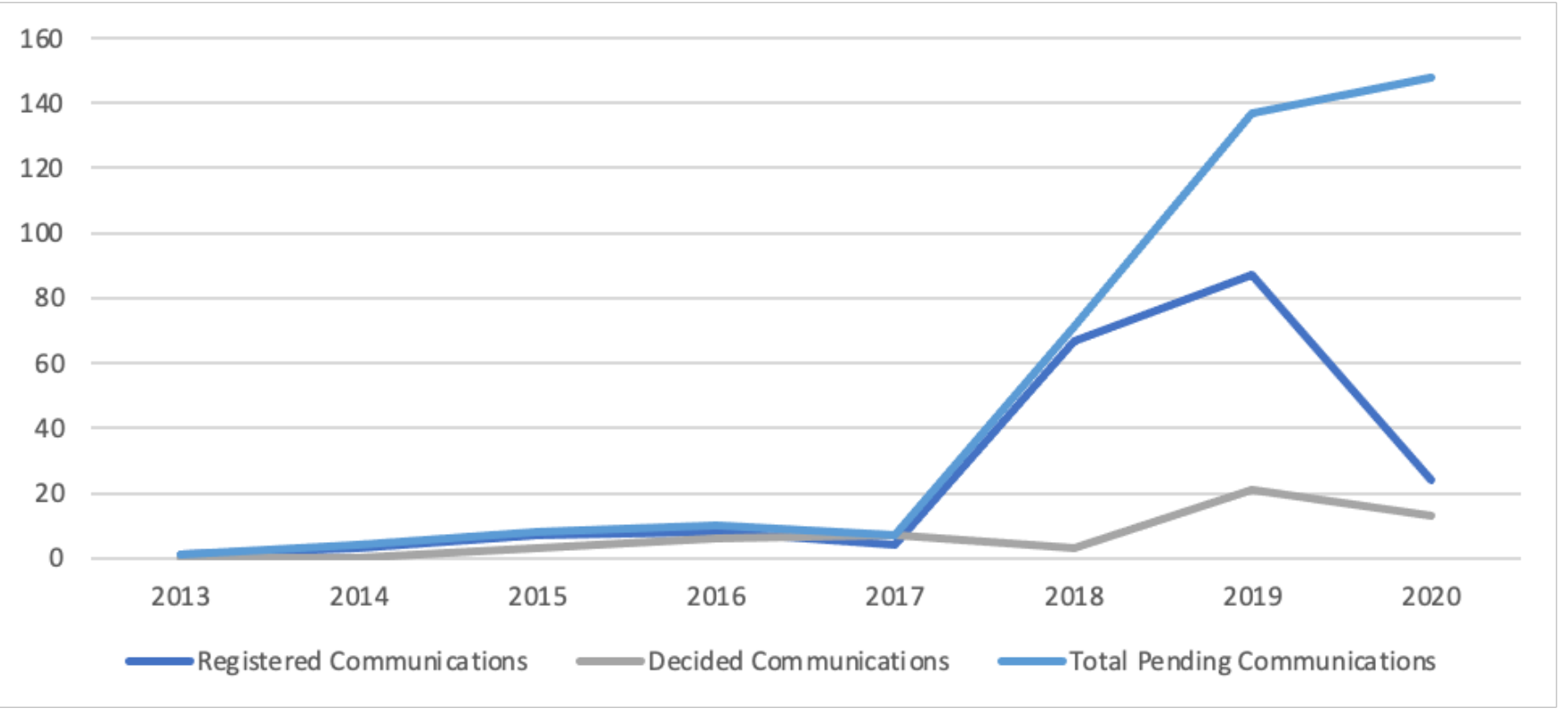

Communications registered, decided and pending. Please note that these graphs are designed to show broad trends in the Committee's jurisprudence and may contain minor inaccuracies.

Type of decision: The Committee only reached a single merits decision in 2020, one fewer merits decision than it made in the previous year. Notably, it continued its recent practice of rendering a large number of discontinuance decisions, although fewer than it had in 2019.

Grounds of inadmissibility: For the third year in a row, none of the Committee inadmissibility decisions related to its competence ratione temporis (inadmissibility on the grounds that the relevant facts had occurred before the entry into force of the Optional Protocol). Unlike the earlier years of the Optional Protocol's functioning, it is now more common for the Committee to declare a communication inadmissible for insufficient substantiation or failure to exhaust domestic remedies. 
A story of continuity: With 12 of 13 decisions addressed to Spain and concerned an alleged violation of the right to adequate housing, the Committee's work in 2020 continues a long established trend. As can be seen from the two graphs on this page, the majority of the decisions that the Committee has rendered through the course of the Optional Protocol's functioning have involved Spain (45 of 53) and the right to housing (36 of 53).

The large number of Spanish housing cases reflects ongoing fallout from its severe post-2008 housing crisis, which left tens of thousands of families in a situation of housing vulnerability. The Committee's power - and willingness - to issue interim measures such as the suspension of an eviction make it an attractive forum to secure the rights of individuals in such a position. In 2018 the Spanish Supreme Court also determined that UN Treaty Body individual decisions were legally binding, increasing the importance of the Committee for Spanish applicants.

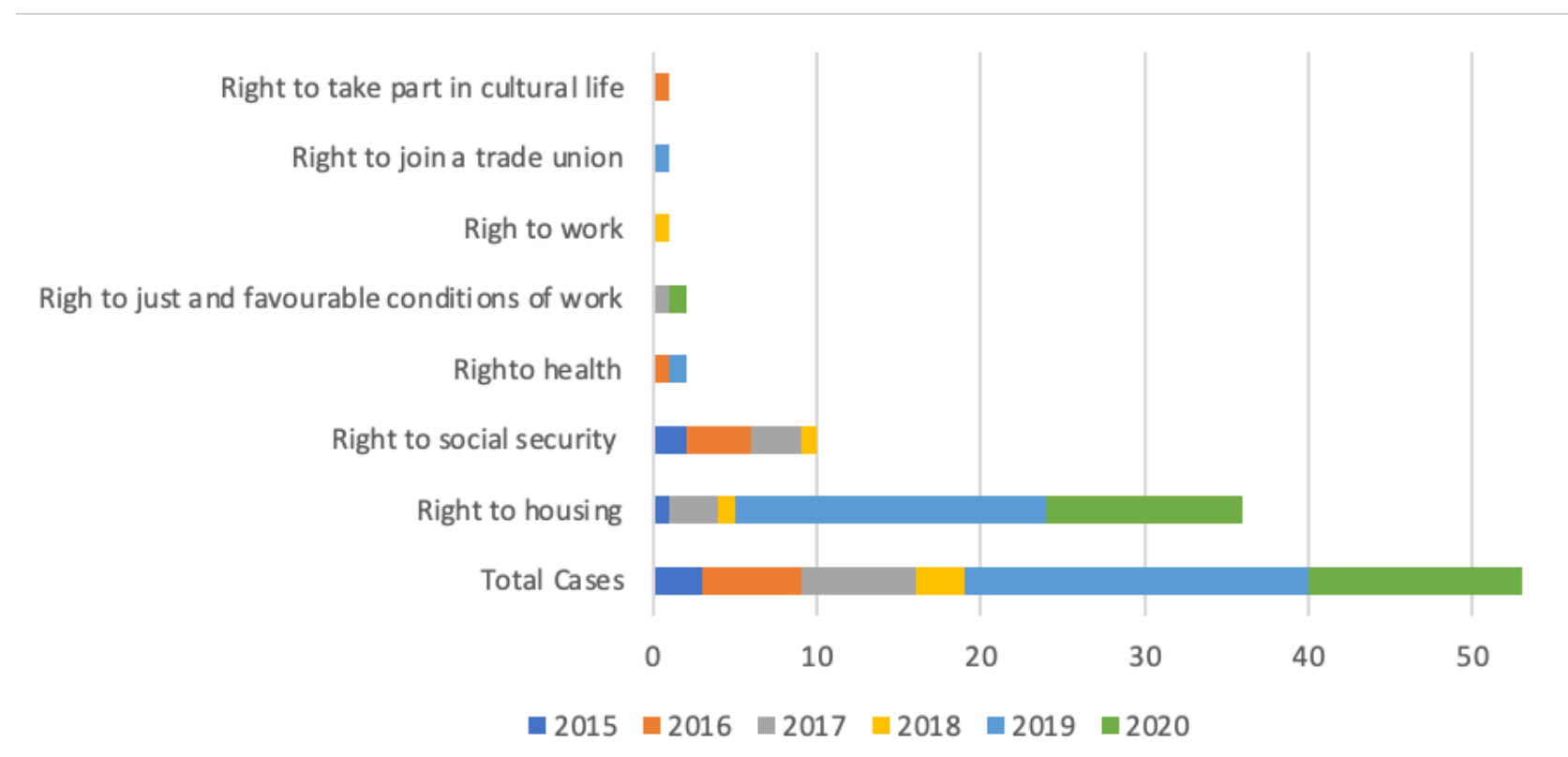

CESCR decisions each year by the Covenant right concerned.

25

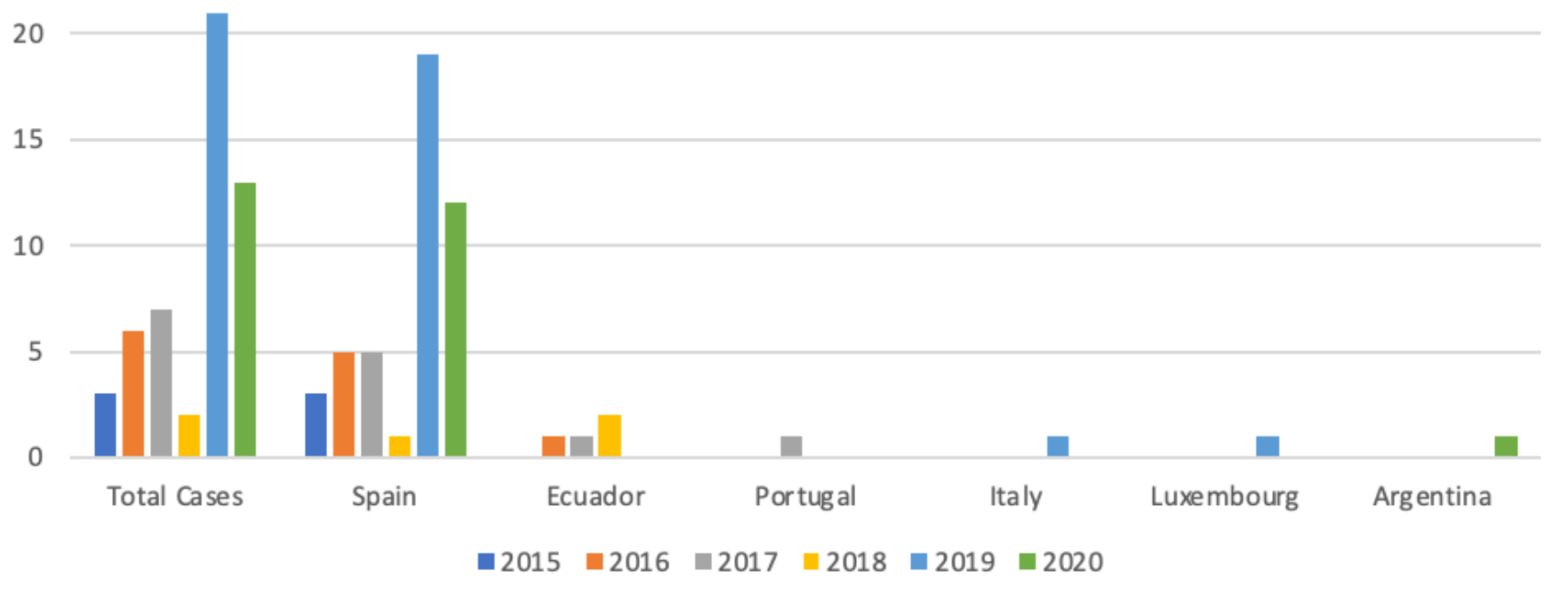

CESCR decisions each year by respondent State.

Minor novelties: Luciano Daniel Juárez was the Committee's first decision concerning Argentina. An additional two communications on the Committee's list of pending cases are also addressed to Argentina, one of which relates to the eviction of the inhabitants of a shantytown and the other which concerns the living conditions of those living in slums. As such, the Committee will soon have an opportunity to diversify its jurisprudence on the right to housing by considering alleged violations in a national context other than Spain.

Luciano Daniel Juárez was also just the second communication in which an alleged violation of the right to just and favourable conditions of work formed the basis of a complaint. Like the first of these communications (Martins Coelho), it was also declared inadmissible. However, the Committee has another two cases concerning this right waiting on its list of pending cases, meaning that it may soon have an opportunity to render its first decision on the substance of the right. 


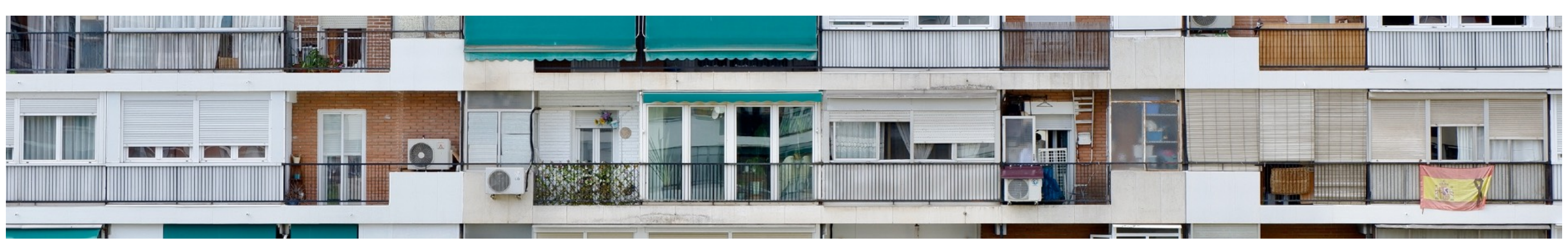

Rosario Gómez-Limón Pardo was the fourth decision in which Spain has been found to be in violation of the Covenant.

\section{Rosario Gómez-Limón Pardo v Spain}

In 2012, a new owner purchased the home in which 73-year-old Rosario Gómez Limón Pardo had lived for most of her life. The new owner sought to terminate Ms Limón Pardo's rental contact, and two years later a Madrid Court ordered her to vacate the property. The community of Madrid offered her shared accommodation or a temporary place in an old person's home, both of which she rejected as unsuitable given her age, diagnosis with cancer, and partial disability.

Ms Limón Pardo submitted a communication to the Committee on Economic, Social and Cultural Rights, but was evicted from her home before a decision had been reached. She claimed that she lacked access to adequate alternative housing and that her eviction thus amounted to a violation of her human right to housing.

Examining this claim, the Committee underscored that States are under an obligation to analyse the proportionality of an eviction in circumstances in which it may result in a violation of an individual's Covenant rights. It added that such an analysis must be carried out by a judicial or other impartial and independent authority with the power to order the cessation of the violation, and to provide an effective remedy.

In the present case, no such proportionality examination had taken place prior to the decision to evict Ms Limón Pardo. Accordingly, the Committee concluded that "the absence of such an assessment constituted a violation by the State party of the author's right to housing".

The Committee proceeded to find that Ms Limón Pardo had been "evicted in spite of the Committee's request for interim measures" and had not been "provided with adequate alternative housing." This failure to respect the requested interim measures was considered to amount to an additional violation of article 5 of the Optional Protocol.

Having established a violation of the Covenant, the Committee recommended that Spain reimburse Ms Limón Pardo's legal costs, examine her housing needs and, if necessary, provide her with suitable alternative housing.

The Committee also made two general recommendations, namely that Spain:

- Ensure that there is a normative framework which allows for persons subject to an eviction order that may violate their Covenant rights to challenge the decision and have authorities examine its proportionality; and

- Establish a protocol for complying with requests for interim measures. 


\section{Luciano Daniel Juárez v Argentina}

Luciano Daniel Juárez was a judge who took part in a competitive examination to fill a vacant position in the Rosario Civil and Commercial Court of Appeal. Whilst his examination results placed him on sixth place on the official roster, he was overlooked in favour of the candidate in ninth position. He alleged this decision was incompatible with article 7 (c) of the Covenant, which protects the right to be promoted to an appropriate higher level.

The Committee noted that the author had not attempted to initiate a judicial dispute or filed an appeal at the domestic level. Whilst the author had cited several domestic cases in an attempt to demonstrate that such efforts would have been futile, the Committee held that "mere doubt as to the chances of a particular remedy's succeeding do not excuse the author from exercising it". The Committee thus found that the communication was inadmissible under article 3(1) of the Optional Protocol, as the author had not exhausted domestic remedies.

\section{AMO and JMU v Spain}

A.M.O., J.M.U. and their three children began occupying an apartment that belonged to a bank after their former home had burned down. After they were subject to numerous eviction orders by Spanish courts, they turned to the Committee and claimed that eviction would violate their right to adequate housing. They added that their low income and the fact that they belong to the Roma community made it impossible to rent on the private market.

The Committee noted that the authors had failed to demonstrate that they had requested alternative housing, had not cooperated with social services, and had not provided evidence of unsuccessful attempts to seek housing on the private rental market.

As such, it concluded that the authors had not demonstrated that they were actual or potential victims of a violation of article 11, and declared the communication insufficiently substantiated for the purposes of inadmissibility under article 3(2) (e) of the Optional Protocol.

\section{B. B. v Spain}

M.B.B and her two children had been occupying a vacant apartment owned by a bank. M.B.B. was subsequently issued with an eviction order, but decided not to appeal the judgement as she had reached an oral agreement with the bank to remain in the property for a few months until she secured social housing. When an eviction date was set, M.B.B. submitted a complaint to the Committee alleging that eviction would constitute a violation of her right to housing. The family was evicted in November 2019.

The Committee acknowledged that M.B.B. had made an agreement with the bank but, as this did not prevent her from appealing the eviction order, found that she had not exhausted domestic remedies (article 3(1) of the Optional Protocol). It added that M.B.B had not made use of emergency social housing solutions offered to her, nor had she provided details on her living conditions since the eviction. As such, it found that the communication was also insufficiently substantiated and inadmissible under article 3(2) (e) of the Optional Protocol.

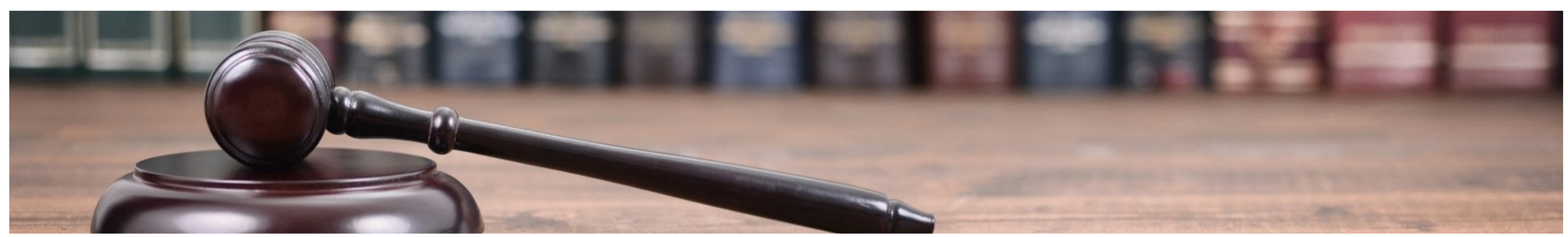

The Committee has yet to deliver a merits decision in a case concerning Argentina, with Luciano Daniel Juárez's communication being found inadmissible. 


\section{Discontinuance Decisions}

Discontinuance decisions made up the majority of the Committee's 2020 decisions, taking up nine of the total 13. Grouping them together masks the variety of different outcomes that resulted.

In five of the Committee's decisions, the discontinuance has been requested by the claimant themselves, with an additional discontinuance requested by both the author and the respondent State party.

These requests were often made due to the fact that the problem that formed the basis of the complaint had been solved. For example, the authors in El Bahri and others $v$ Spain requested that the Committee discontinue their communication as their family had been granted housing by the public administration. This request had followed the Committee's call for Spain to adopt interim measures by suspending the family's eviction or providing them with adequate alternative housing. It is notable, therefore, that the Committee may exert an influence that extends beyond its substantive decisions.

Several discontinued communications reveal a more equivocal outcome. In D. E. B. and L. M., for example, the authors requested that their communication be discontinued as they had found rented accommodation in a shared apartment. However, this had occurred after they had been evicted from their home.

A number of discontinuance decisions also result from the claimant's lack of engagement with the process. For example, in N.J.M.C. et al v Spain, following a State request, the Committee opted to discontinue the communication as the author "had not submitted the documentation requested on numerous occasions by the Committee or claimed that she was unable to provide it".

Similarly, two communications were discontinued by the Committee as they had been unable to contact the author. Both of these decisions were rendered over 20 months after the date of their initial registration.

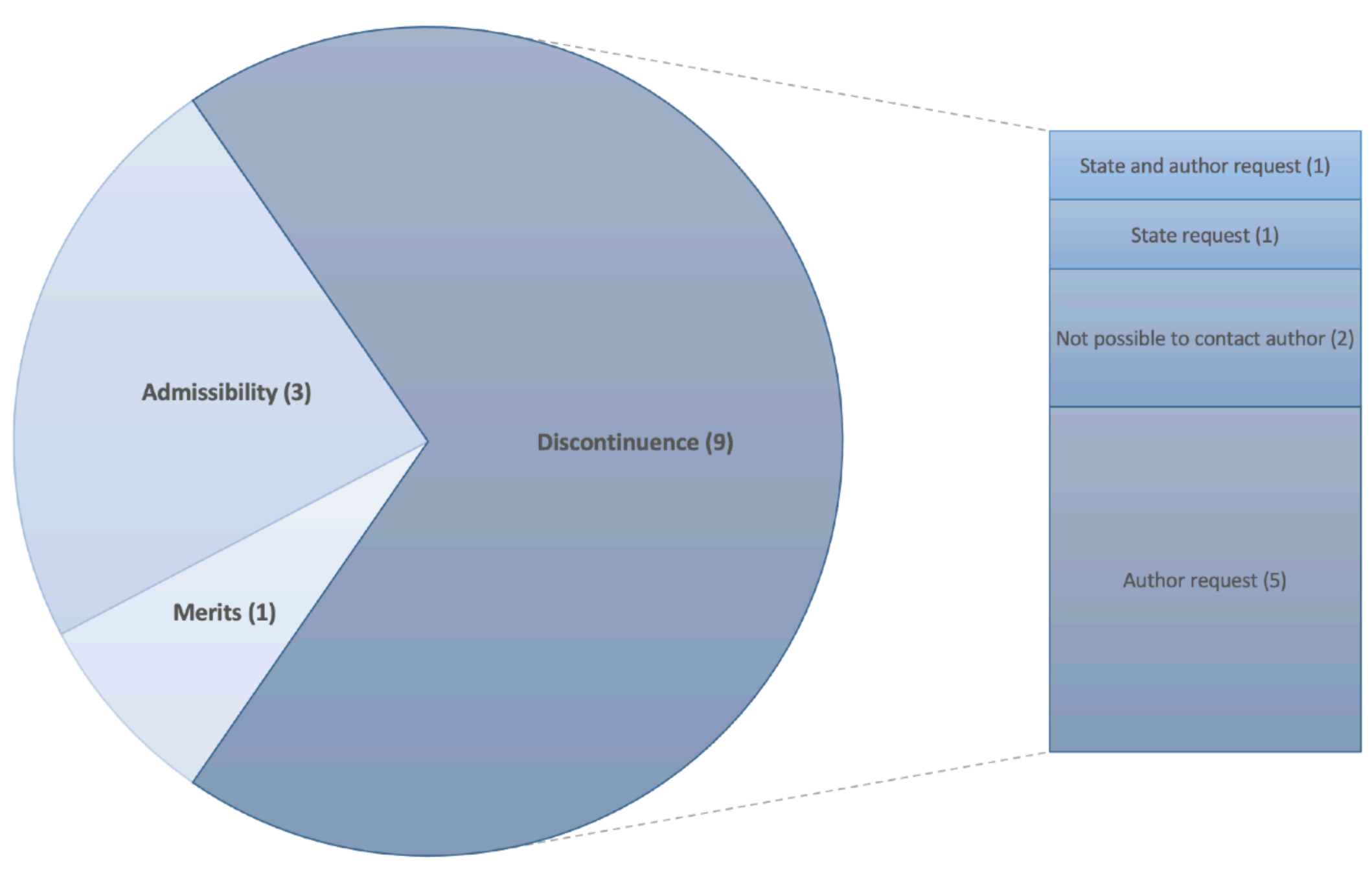

2020 discontinuance decisions according to type. 


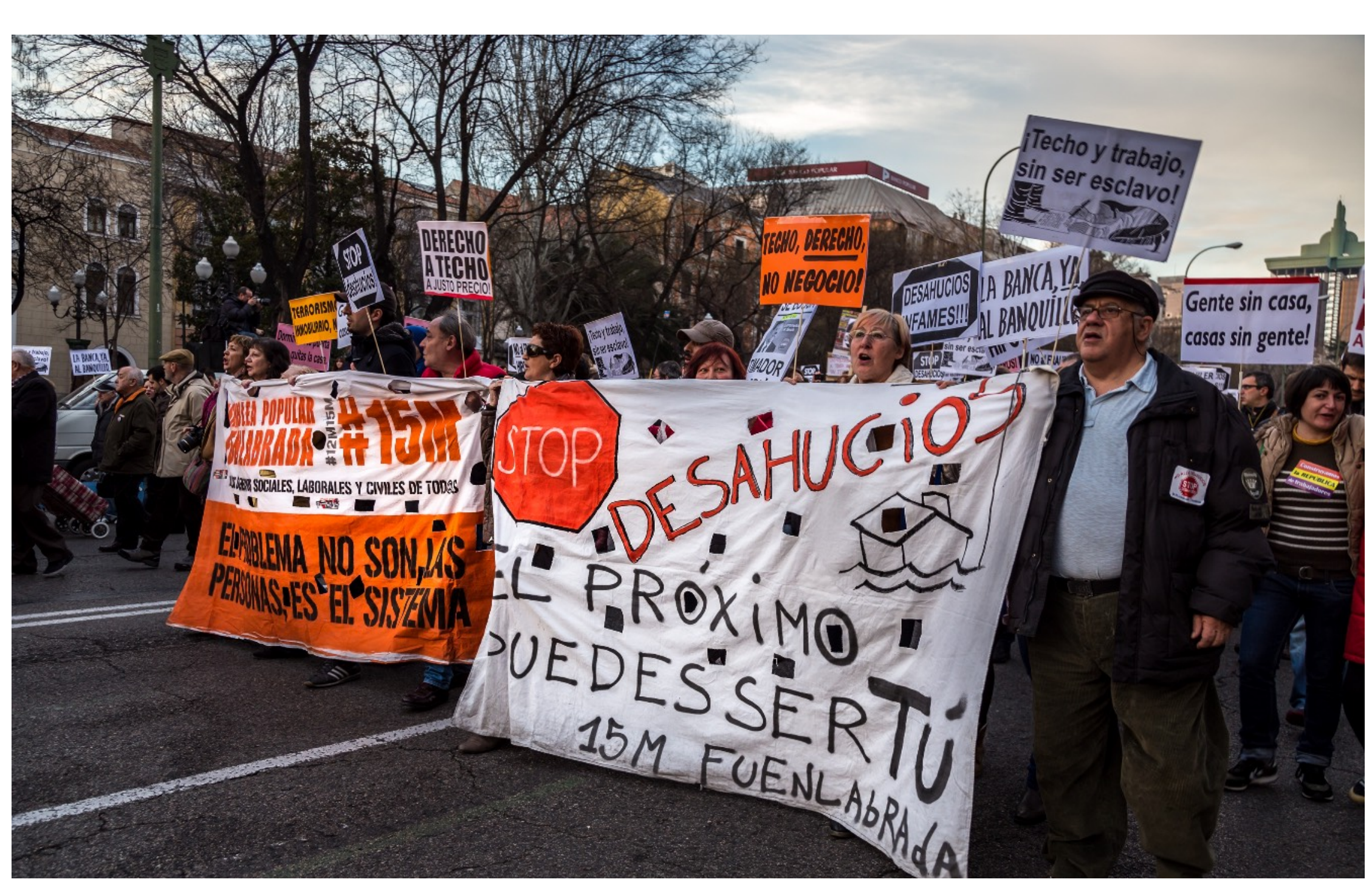

I.D.G v Spain was the first decision that the Committee made under the Optional Protocol.

\section{Follow Up}

2020 saw the

Committee release its second report on its follow-up activities under the Optional
Protocol. The report contained an update on the implementation of three previous decisions:
- I.D.G. v. Spain;

- Trujillo Calero v. Ecuador; and

- S.C. and G.P. v. Italy.

\section{I.D.G. v Spain}

In I.D.G. v Spain (2015), the Committee had found that the public posting of notice that mortgage enforcement proceedings had commenced had not enabled the author to defend the enjoyment of her home and, as such, constituted a violation of her right to adequate housing. Amongst its various recommendations, the Committee called on Spain to reimburse the author for legal costs, ensure the auction of her property did not proceed without due process, and ensure that notification by public posting in mortgage enforcement procedures is limited to situations in which all means of serving notice in person have been exhausted.

The Committee adopted a first follow-up in 2019, finding that its General

Recommendations had been "satisfactorily implemented" as Spain had, amongst other things, followed the Committee's call to amend its legislation so as to limit the use of notification by public posting in mortgage enforcement proceedings. Although no auction of the authors property had taken place, compensation for legal costs was still pending settlement and the State was invited to provide further information on this matter.

In the Committee's second follow-up report in 2020 it noted that judicial authorities had informed the author of the channel through which she may make a claim for compensation, yet that she had not yet submitted such a claim. That the recommendation had not been

implemented could thus not be attributed to the State party. As such, the Committee concluded the follow-up process, the very first time that it has done this. 


\section{Trujillo Calero v Ecuador}

In Trujillo Calero v Ecuador (2018), the Committee had determined that a decision to disaffiliate an unpaid care worker from a retirement scheme due to an eight month pause in voluntary pension payments amounted to a violation of her right to social security, nondiscrimination and gender equality.

The Committee had recommended that Ecuador provide the author with compensation and the benefits that she was entitled to, and had outlined a raft of general recommendations, such as calling on the State to ensure penalties imposed on affiliates of social security institutions are proportionate.
The Committee's 2020

follow-up report was its first in relation to this case.

The Committee welcomed the fact that the State had entered into negotiations with the author over the monetary value of the pension and the compensation that the author will receive and encouraged these negotiations to continue.

However, it considered that several of its recommendations had "not yet been implemented" and invited further information from the State, continuing the follow-up procedure.

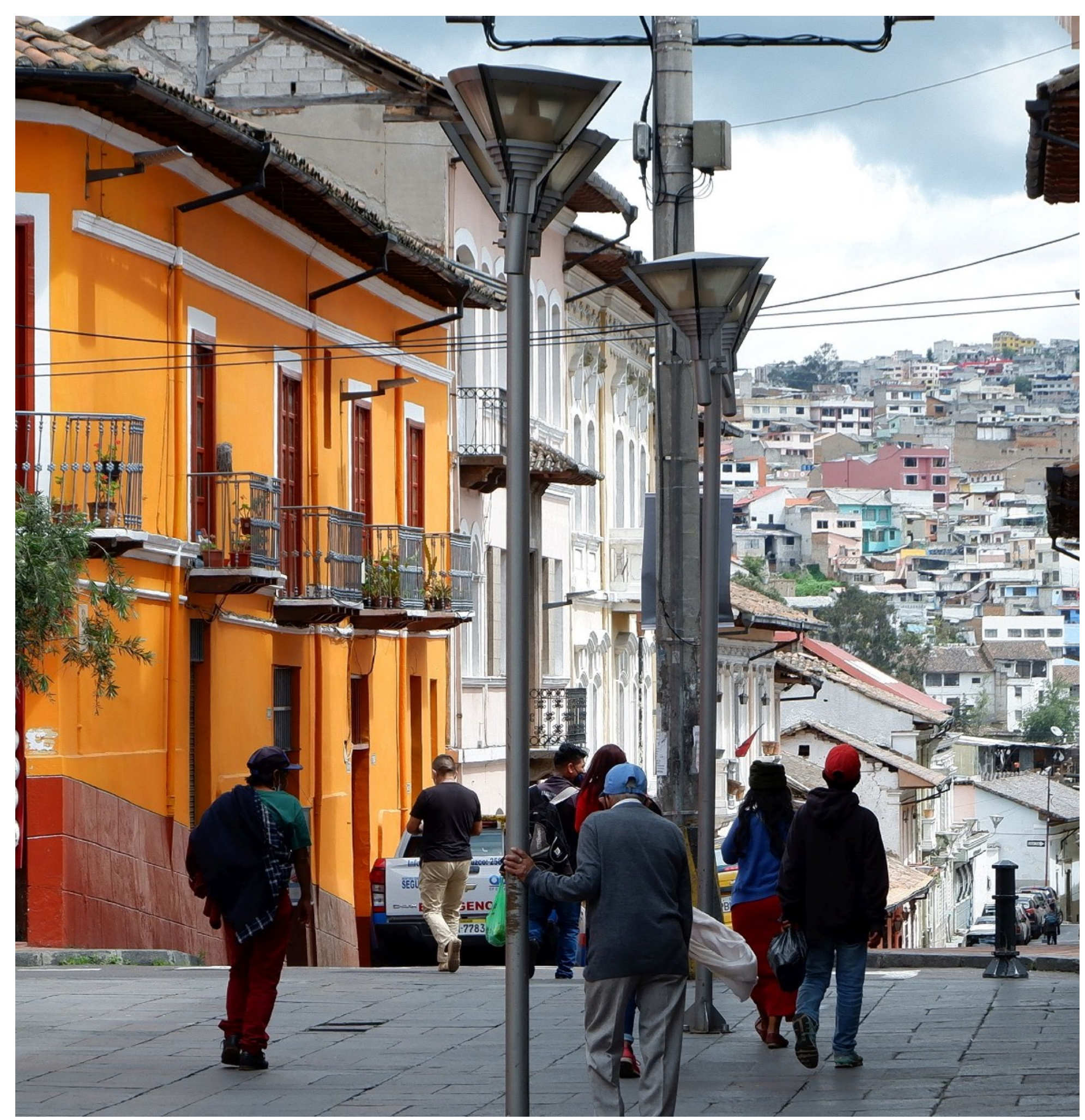

Trujillo Calero remains the only case in which the Committee has found a violation of the right to social security. 


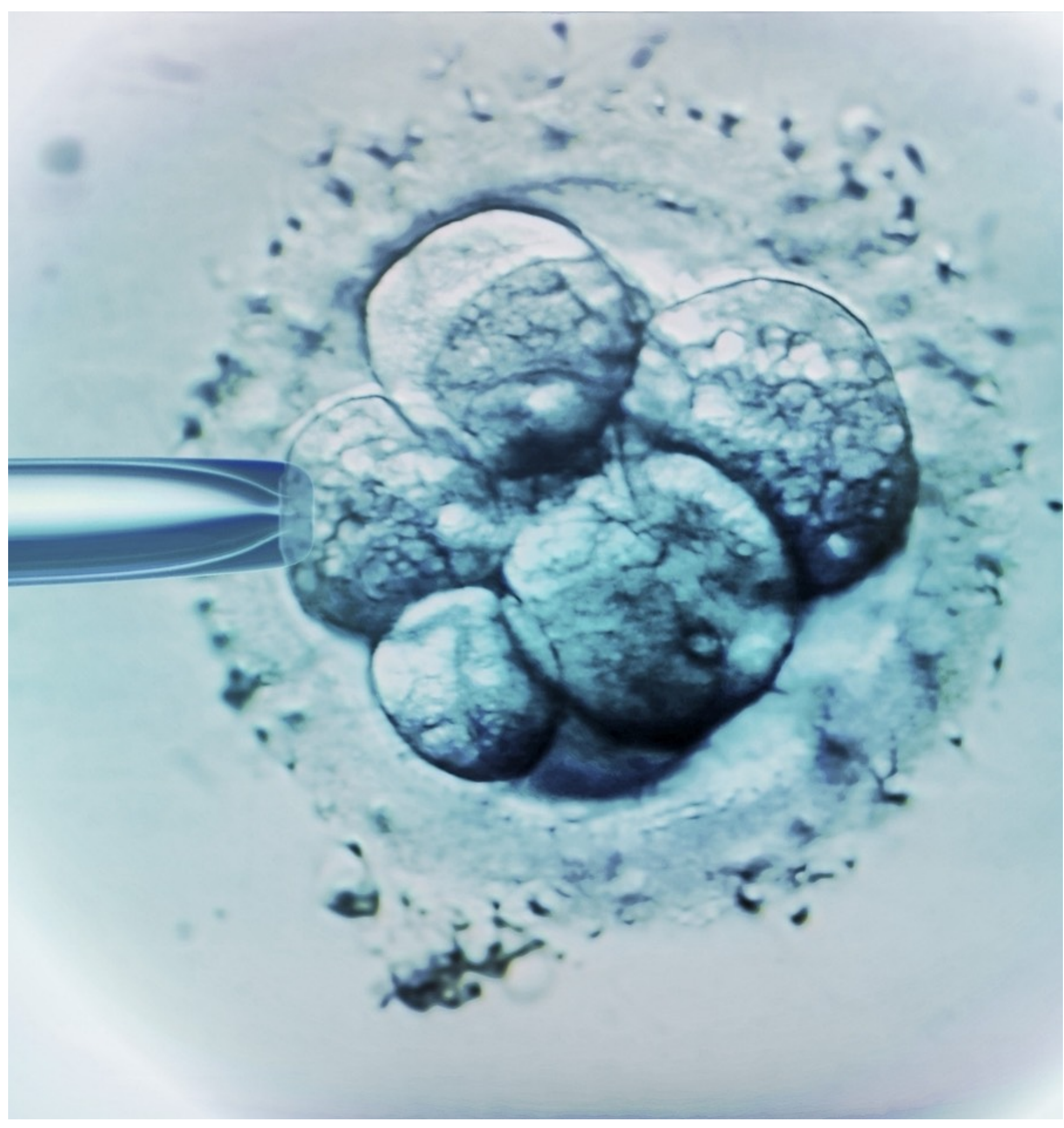

S.C had been informed that it was not possible to revoke her consent to in vitro fertilization treatment.

\section{S.C. and G.P. v Italy}

In S.C. and G P. v. Italy (2019) the Committee found that a prohibition on the revocation of consent to have an embryo transferred into a woman's uterus constituted a violation of her right to health.

Accordingly, it had made several recommendations, including that the State award S.C. compensation for damages suffered, and adopt legislative and/or administrative measures to guarantee access to all reproductive treatments generally available and to allow all persons to withdraw their consent to the transfer of embryos for procreation.

The Committee's 2020 follow-up report was also the first in relation to this case.
The Committee acknowledged that the authors had requested compensation, and took note of the fact that a Decree on the expression of informed consent had been adopted, as well as a series of regional measures on consent.

However, there was no indication that the authors had received a response to their request for compensation, nor had any further detail on the Decree or the regional measures been provided.

As a result, the Committee considered that its recommendations had "not yet been implemented" and opted to continue the follow-up procedure. 


\section{Thematic work in 2020}

\section{GENERAL COMMENT ON SCIENCE AND ECONOMIC, SOCIAL AND CULTURAL RIGHTS}

The Committee decided to focus its 25th General Comment on science, considering it "one of the areas of the Covenant to which States parties give least attention in their reports and dialogues with the Committee". It concentrated on the right of everyone to enjoy the benefits of scientific progress and its applications (article 15(1)(b) of the Covenant), whilst also seeking to develop the relationship between science and ESC rights more broadly.

After setting out the definition of key norms, the General Comment identifies five essential elements of the right to participate in and enjoy the benefits of scientific progress: i) "Availability", meaning scientific progress is taking place and scientific knowledge is widely disseminated;

ii) "Accessibility", meaning scientific progress and its applications should be accessible for all persons, without discrimination;

iii) "Quality", meaning there is access to the most advanced, up-to-date and generally accepted science available at the time; iv) "Acceptability", meaning efforts should be made to ensure science is explained and its applications are disseminated in a manner that facilitates acceptance in different cultural and social contexts; and v) protection of the freedom of scientific research.

The General Comment sets out State obligations, highlighting that protection is needed for specific groups that experience systemic discrimination in their enjoyment of the right to science. Women, persons with disabilities, persons living in poverty, and indigenous peoples are all considered to be frequently underrepresented in scientific activity.

The Committee also identifies specific and core obligations, noting, for example, that States have an obligation to respect, respect, protect and fulfil the right to science. It stresses that when allocating public resources, priority should be "given to research in areas where there is the greatest need for scientific progress in health, food and other basic needs" relating to ESC rights.

In Section VI, the Committee discusses the importance of the duty of international cooperation. It highlights pandemics as a crucial example of the need for cooperation, given that "viruses and other pathogens do not respect borders". The Committee also draws attention to extraterritorial obligations, including to regulate multinational companies and ensure intellectual property regimes foster the enjoyment of the right to participate in, and enjoy the benefits of, scientific progress and its applications.

The Committee concludes by considering national implementation of the right to participate in, and to enjoy the benefits of, scientific progress and its applications. It recommends that States put in place a normative framework, develop a national plan of action, identify appropriate indicators, and establish effective mechanisms to prevent violations.

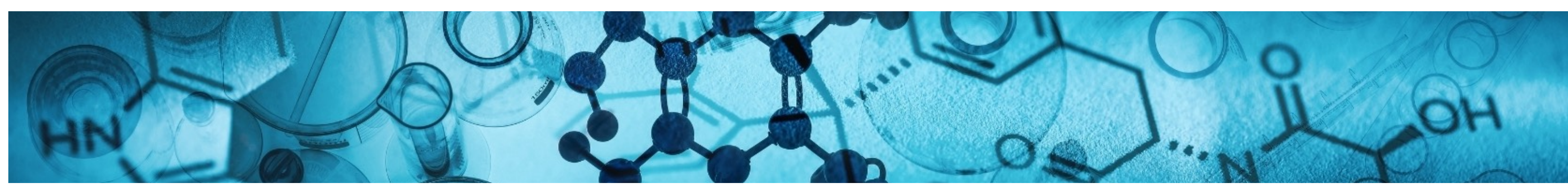

The General Comment is of great relevance to the covid-19 pandemic, the on-going climate crisis and debates about artificial intelligence technologies. 
As the full scale of the threat posed by COVID-19 became clear, the Committee published a Statement on coronavirus and ESC rights. In doing so, it sought to identify the most significant impacts that the pandemic was having on ESC rights, as well as to offer guidance on how State parties could combat coronavirus in a manner that was consistent with their human rights obligations.

The Statement began by drawing attention to the fact that decades of underinvestment has left public health-care systems and social programmes ill-equipped to deal with this global health challenge. It highlighted the fact that older persons and those with pre-existing health conditions are particularly vulnerable, whilst groups such as prisoners, residents of informal settlements, delivery workers, and health care workers are at a heightened risk of infection. It added that indigenous peoples, refugees and asylum seekers often lack access to necessary resources and services, such as water, soap, and COVID-19 testing facilities.

The Statement also considered the effect that the pandemic is likely to have on inequalities. It noted that those living in poverty are particularly disadvantaged by measures necessary to contain the spread of the disease, that the move to online education will have an impact on poorer learners who cannot access technological devices, and that the pandemic threatens to deepen gender inequalities "as the burden of caring for children at home and sick or older family members falls disproportionately on women".

The Committee recommended that States take a series of urgent measures in order to ensure Covenant rights are protected and fulfilled during the crisis. It stressed that States should ensure the response to coronavirus is "based on the best available scientific evidence" and that any measures that limit rights are necessary, reasonable and proportionate. It also added that they should engage in international cooperation, ensure health care workers are provided with proper personal protective equipment (PPE), and adopt targeted measures to mitigate adverse effects on vulnerable groups, such as introducing moratoria on evictions.

Looking forward, the Committee called upon States to "ensure that the extraordinary mobilization of resources to deal with the COVID-19 pandemic provides the impetus for long-term resource mobilization towards the full and equal enjoyment of the economic, social and cultural rights enshrined in the Covenant."

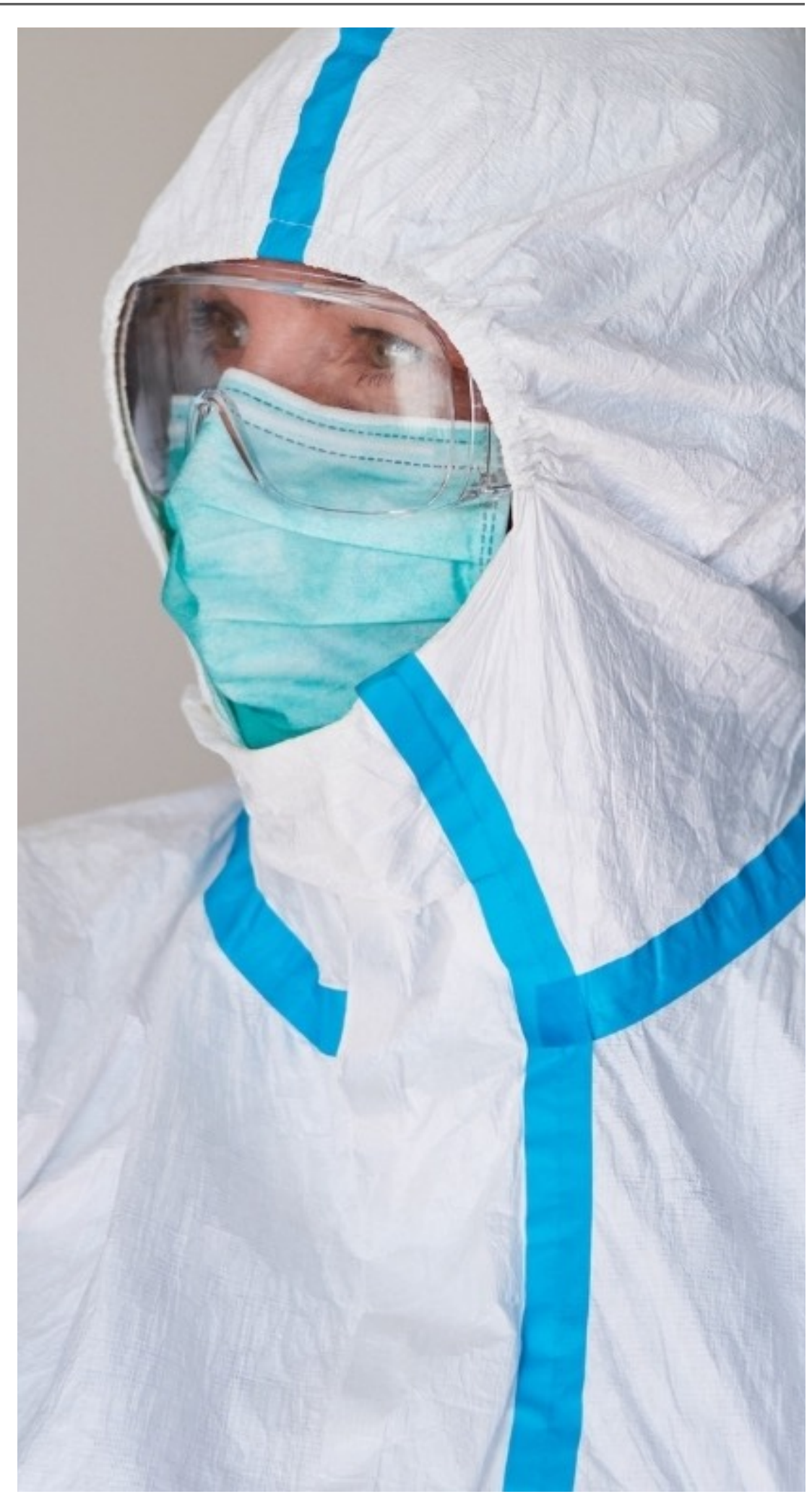

PPE shortages have been a major issue for many States. 


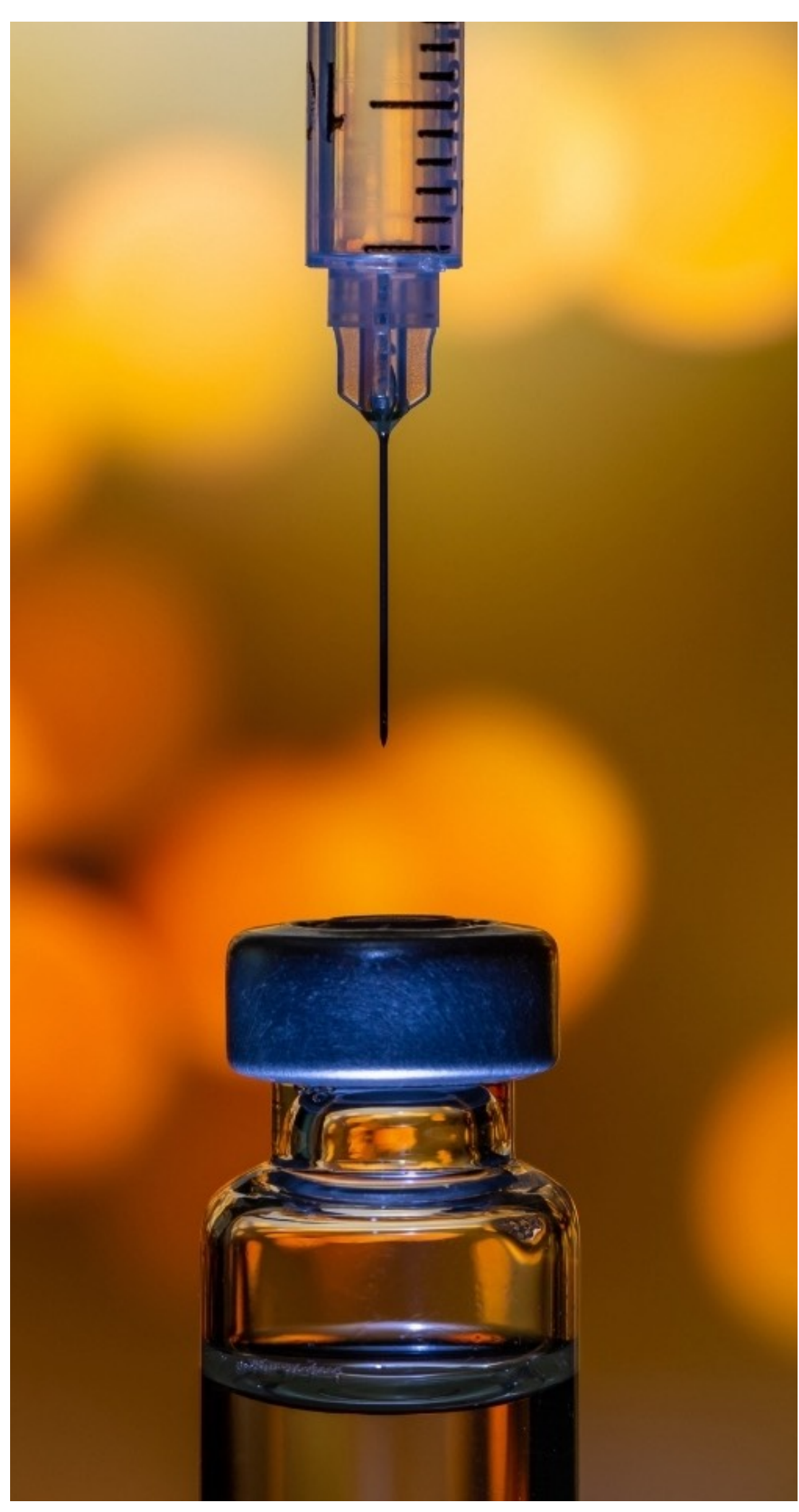

Vaccine inequality continues to plague the globe.
October and November 2020 saw a flurry of important developments related to COVID-19 vaccines. Several promising vaccine candidates were announced and a request was submitted to the World Trade Organization which called for sections of the Agreement on Trade-Related Aspects of Intellectual Property Rights (TRIPS) to be waived so as to allow States to choose not to enforce patents on coronavirus vaccines. As the rollout of vaccination programmes loomed on the horizon, the Committee considered it necessary to intervene and remind State parties of their Covenant obligations.

The Committee began its Statement by making clear that every person has the right to enjoy the benefits of scientific progress and the right to enjoy the highest attainable standard of health, including to access immunisation programmes against major infectious diseases. It left little doubt that these rights "imply that every person has a right to have access to a vaccine for COVID-19...."

The Statement proceeded to set out the State obligation to take all measures necessary, to the maximum available resources, to guarantee access to vaccines without discrimination. It underscored that the right to health entails that States must ensure health facilities, services and goods, including vaccines, are available, accessible, acceptable and of good quality. Whilst it is acknowledged that prioritisation of access to vaccines is "unavoidable", such prioritisation "must be based on medical needs and public health grounds."

The Committee considered the issue of intellectual property (IP) in relative depth, noting that whilst it is fair that the companies that have developed a vaccine receive reasonable compensation, State parties to the Covenant have a duty to prevent IP regimes from undermining ESC rights, for example by making vaccines inaccessible to developing countries. It recommended that States make use of the flexibilities built into the TRIPS agreement, but, accepting that these "will in all likelihood... be insufficient to face adequately the pandemic", also called for the proposed waiver to be "considered and implemented".

Finally, the Committee also outlined the State duty of international cooperation and assistance to ensure universal equitable access to vaccines. It stressed that there should not be "health isolationism or to a race for COVID-19 vaccines", which "runs counter to the extraterritorial obligations of States to avoid taking decisions that limit the opportunity of other States to realise their right to health". Setting out an alternative course of action, the Committee urged States to ensure that the distribution of vaccines is organised through mechanisms of international cooperation, such as the COVAX Global Vaccines Facility. 


\section{Working methods and procedural information}

\section{Predictable review cycle and simplified reporting procedure}

The Committee finalised a methodology for the adoption of lists of issues prior to reporting (LOIPR). It also decided that, subject to resources, it would introduce an eight-year predictable review cycle for review of State party reports and offer the simplified reporting procedure to all States that wished to make use of it. The changes would ensure that the Committee engages with all 171 State parties to the Covenant but - due to ongoing resource constraints and the increased costs that this would imply - they are yet to have been made operational.

The Committee's decision to make these alterations to its working methods was guided by the discussions relating to the 2020 review of the treaty body system, including General Assembly resolution 68/268, the position of the Chairs of the treaty bodies, and the views of States and other stakeholders. Whilst it is hoped that uptake of this streamlined procedure will reduce the reporting burden on States, the Committee should be careful to ensure this does not come at the cost of the effectiveness of review.

\section{Coordination with the Human Rights Committee}

The CESCR continues to hold exchanges and engage in cooperation with the Human Rights Committee, as well as other Committees. The Committee's latest changes to its working methods entails that its approach to State reporting is now better aligned with that of the Human Rights Committee.

The CESCR and the Human Rights Committee, which will both review countries on an 8-year cycle, have agreed to synchronise the timing of their reviews. They have decided to coordinate the development of LOIPR that concern the same country, so as to further focus the process and reduce unnecessary overlap and repetitions in States parties' reports and concluding observations.

\section{Draft Rules of procedure under the Optional Protocol}

The Committee's Working Group on Individual Communications had been mandated to develop a draft of the revised Rules of Procedure under the Optional Protocol to the ICESCR. The Draft Rules contain several proposed procedural innovations, including a Pilot Views procedure that is designed to enable the Committee to both tackle its growing backlog and better address structural rights violations. The revised draft Rules were published and opened for public consultation in 2021.

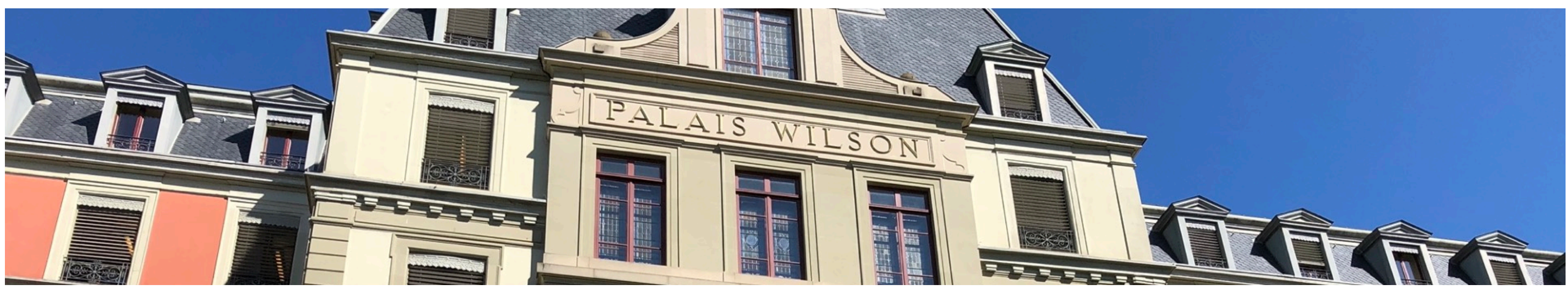

Palais Wilson, the home of the Committee, sits on the shores of Lake Léman in Geneva. 


\section{The Global Initiative for Economic, Social and Cultural Rights}

Together with partners around the world, the Global

Initiative for Economic, Social and Cultural Rights works to advance the realisation of economic, social and cultural rights, tackling the endemic problems of poverty, social injustice and inequality through a human rights approach.

In addition to the annual Yearbook on the Committee for Economic, Social and Cultural Rights, GI-ESCR also provides regular updates from Geneva on significant developments that relate to the field of ESC rights. This includes updates from each session of the Committee for Economic, Social and Cultural Rights, as well as each session of the Human Rights Council. You can subscribe here.

On GI-ESCR's recently published CESCR Jurisprudence webpage page you can find a summary of each of the communications that the Committee has decided; a database with statistics on all of the Committee's decisions; and analysis of the most significant trends that have emerged from the Committee's jurisprudence.

GI-ESCR also hosts an Individual Communication Guide, which includes a step-

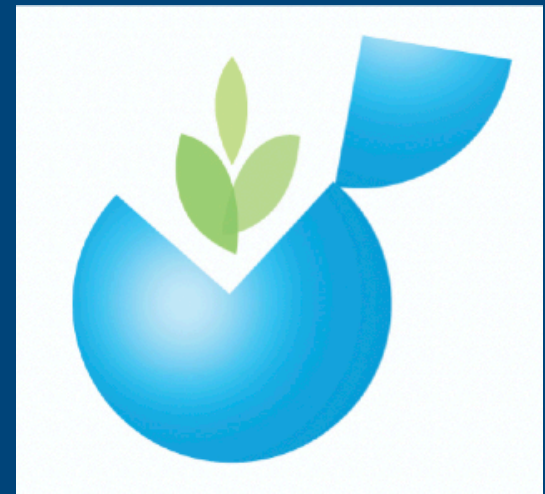

by-step explanation of the different stages of the individual communication process and a collection of resources where additional information may be found.

We are always interested in learning of how the Yearbook is received. Please feel free to send us any comment or question regarding the Yearbook at info@gi-escr.org.

For further information about our work, please consult our website at www.gi-escr.org.

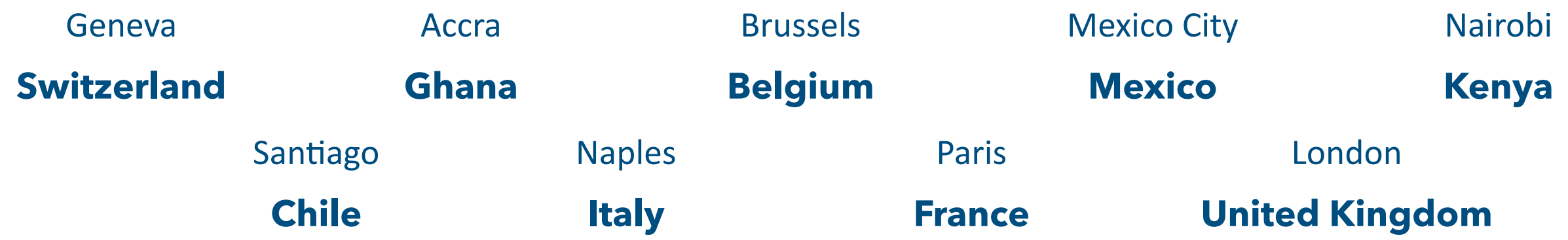

